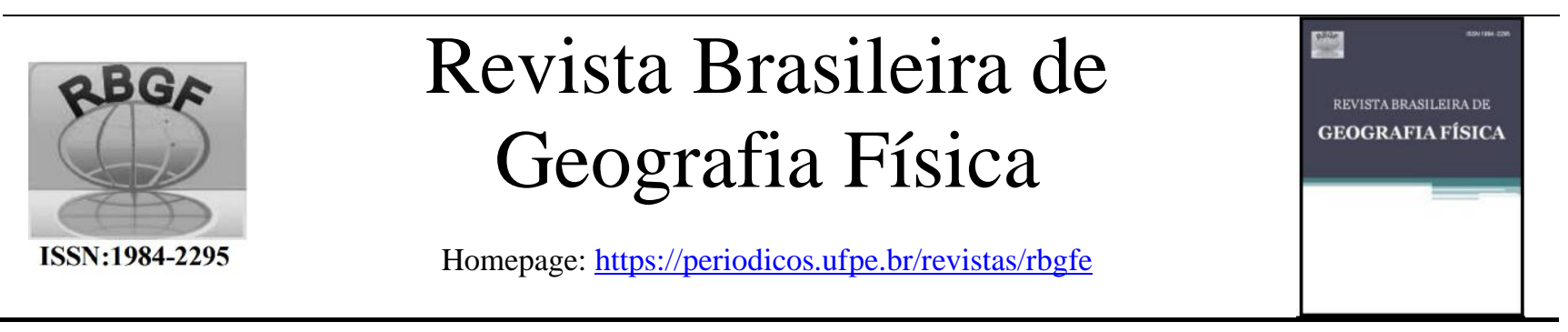

\title{
Análise de índices climático para avaliação do efeito de mudanças climáticas
}

\author{
Guilherme Giorgi Leite de Almeida ${ }^{1}$; Anderson Luiz Ribeiro de Paiva ${ }^{2}$; Leidjane Maria \\ Maciel de Oliveira ${ }^{3}$; Haylla Rebeka de Albuquerque Lins Leonardo ${ }^{4}$
}

\begin{abstract}
${ }^{1}$ Graduando, Departamento de Engenharia Civil e Ambiental, Universidade Federal de Pernambuco (UFPE), Recife, Pernambuco, Brasil, guisystem@ @otmail.com; ${ }^{2}$ Professor do Departamento de Engenharia Civil e Ambiental e da PósGraduação em Engenharia Civil, Universidade Federal de Pernambuco (UFPE), Recife, Pernambuco, Brasil, anderson.paiva@ufpe.br; ${ }^{3}$ Professora do Departamento de Engenharia Civil e Ambiental e da Pós-Graduação em Ciências Geodésicas e Tecnologia da Geoinformação, Universidade Federal de Pernambuco (UFPE), Recife, Pernambuco, Brasil, leidjaneoliveira@hotmail.com; ${ }^{4}$ Graduanda, Departamento de Engenharia Civil e Ambiental, Universidade Federal de Pernambuco (UFPE), Recife, Pernambuco, Brasil, hayllarebeka.hr@gmail.com.
\end{abstract}

Received 01 Jan 2020; accepted 20 March 2020

\section{RESUMO}

Neste presente artigo objetivou-se analisar mudanças climáticas ocorridas no Estado de Pernambuco, observando os impactos no aspecto climático por meio de índices físicos, com enfoque na região semiárida, caracterizada por problemas de escassez hídrica. A partir da avaliação da variabilidade temporal da precipitação em diversas bacias hidrográficas do Estado empregando o índice de anomalia de chuva (IAC), assim como índice de aridez (IA); análise da tendência das séries pluviométricas, e por fim identificação das áreas com vulnerabilidade à desertificação, a partir de estudos realizados em séries temporais no período entre 2000 e 2018 , com dados de 13 postos pluviométricos. Para realizar o estudo, foram utilizados testes estatísticos nas análises de tendências, por meio do software Trend e pela regressão linear; para o cálculo do índice de anomalia de chuvas foram realizados o preenchimento de falhas pelo método do vetor regional e a consistência dos dados foi realizada pelo método da dupla massa. Utilizaram-se os dados pluviométricos obtidos no site da APAC para os municípios de três mesorregiões Pernambucanas (Metropolitana, Agreste e Sertão). Entre os postos analisados, apenas os seguintes postos apresentaram tendência: Belo Jardim, Caruaru, Serra Talhada, Betânia, Ibimirim, Recife, Abreu e Lima e Camaragibe. Todos apresentaram tendências de queda na precipitação. Em relação à vulnerabilidade ao processo de desertificação, observado por meio do índice de anomalia de chuvas, foi observado que as mesorregiões do Sertão Pernambucano, e Agreste Pernambucano apresentaram maiores quantidades de períodos secos ou muito secos.

Palavras-chave: Series Pluviométricas; Índices Físicos; Desertificação

\section{Climate index analysis for evaluating the effect of climate change}

\begin{abstract}
The present article aimed at analyzing climatic changes occurring in the State of Pernambuco, observing the impacts on the climatic aspect through Physical Indices, focusing on the semi-arid region, characterized by problems of water scarcity. From the evaluation of the temporal variability of precipitation in several watersheds of the state using the Rainfall Anomaly Index (IAC), as well as aridity index (IA); analysis of the Trend of the rainfall series, and finally identification of the areas with vulnerability to desertification, based on studies carried out in time series between 2000 and 2018, with data from 13 pluviometric stations. In order to carry out the study, statistical tests were used in the analysis of Trends through Trend Software and Linear Regression; for the calculation of the Rainfall Anomaly index, Fault Filling was performed by the Regional Vector method and the data consistency was performed by the Double Mass Method. The rainfall data obtained from the APAC website for the municipalities of three meso-regions of Pernambuco (Metropolitan, Agreste and Sertão) were used. Among the stations analyzed, only the following stations had a tendency: Belo Jardim, Caruaru, Serra Talhada, Betânia, Ibimirim, Recife, Abreu e Lima, and Camaragibe. All presented Fall Trends in precipitation. In relation to the vulnerability to the desertification process, observed through the rainfall anomaly index, it was observed that the mesoregions of Sertão Pernambucano and Agreste Pernambucano presented higher amounts of dry or very dry periods.
\end{abstract}

Keywords: Pluviometric Series; Physical Indices; Desertification 


\section{Introdução}

Pernambuco é o estado do país mais pobre em quantidade de água por habitante. Além disso, aproximadamente $89 \%$ do território do Estado estão inseridos na região semiárida, onde as chuvas são escassas e ocorrem de forma concentrada em poucos meses do ano. Em 2019, o estado de Pernambuco apresentou um dos municípios na sexta posição no ranking da seca, como pode ser observado na Figura 1. As características morfológicas, por sua vez, em geral não permitem a construção de grandes reservatórios de água. Pernambuco possui também grande variabilidade sazonal e interanual de seus recursos hídricos e enfrenta problemas frequentes com ciclos de enchentes e secas. Portanto, os desafios da gestão de recursos hídricos no estado são ainda maiores do que em outras regiões do Brasil, especialmente pela diversidade de problemas envolvidos.

Segundo dados do site Letras Ambientais (2019), e segundo um relatório do Centro de Estudos e Pesquisas em Engenharia e Defesa Civil (CEPED, 2019), no período de 1995-2014, os danos materiais e prejuízos (públicos e privados) causados por desastres naturais, derivados de eventos climáticos no Brasil, foram estimados em R\$ 100 bilhões. Deste total, cerca de $75 \%$ estão diretamente vinculados às estiagens e secas, a afetam frequentemente o Nordeste e as demais regiões do Brasil. No Nordeste, o custo total de danos e prejuízos, derivados de eventos climáticos, foi cerca de $\mathrm{R} \$ 47$ bilhões. $\mathrm{O}$ valor inclui os prejuízos privados nos setores da agricultura, pecuária, indústria e serviços.

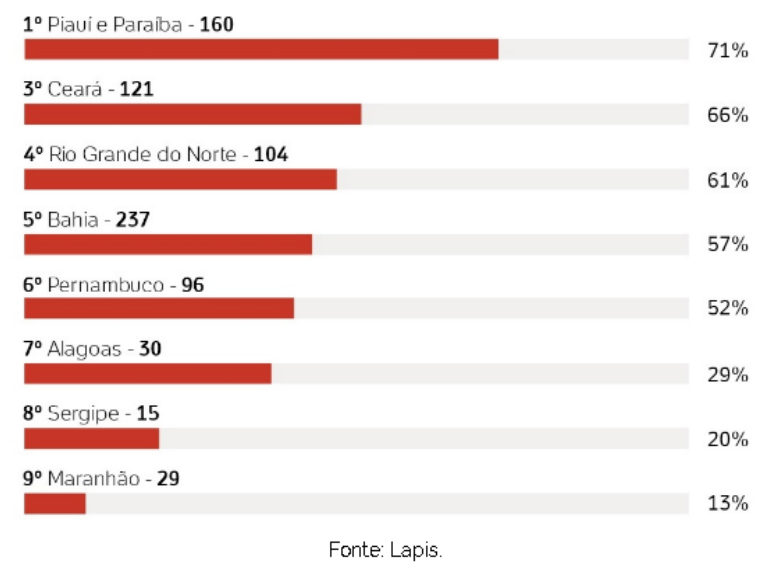

Figura 1. Ranking da seca nos municípios do Nordeste. Fonte: Letras Ambientais (2019).

Segundo Yevjevich (1972) define tendência em uma série temporal como uma mudança sistemática e contínua em qualquer parâmetro de uma dada amostra, excluindo-se mudanças periódicas ou quase periódicas Para Silva et al. (2017), a análise da tendência de séries históricas de precipitação é uma das maneiras de se determinar a ocorrência de mudança climática local. Segundo Freitas (1999) pesquisas realizadas pela Organização Mundial das Nações Unidas OMM mostraram que um terço da população mundial vive em regiões de moderado a alto estresse hídrico, e que as estatísticas demonstraram claramente que nos próximos 30 anos a situação global das reservas tenderá consideravelmente a piorar, caso não ocorram ações emergenciais para melhoria da oferta em relação à demanda d'água.

Segundo os estudos de Nimer (1979), em que foi comparado os percentuais pluviométricos de meses consecutivos com os totais anuais das zonas da Mata, Agreste e Sertão do estado de Pernambuco, verificou-se que além do Sertão Pernambucano possuir os totais anuais muito inferiores em relação aos apresentados pela Zona da Mata, seu regime anual é muito mais concentrado em poucos meses.

A motivação para o presente trabalho é incrementar o conhecimento das diferentes bacias hidrográficas no estado de Pernambuco e projetar cenários de possíveis impactos sobre os recursos hídricos de mudanças climáticas, mudanças de uso do solo e medidas adaptativas e de gestão da oferta, da demanda e de infraestruturas hídricas. Dada à importância das mudanças climáticas, do crescente aumento de eventos extremos de secas no Sertão e Agreste e da necessidade de melhor compreender as escalas da variabilidade das precipitações pluviométricas, o presente artigo tem como objetivo avaliar a variabilidade temporal da precipitação na bacia hidrográfica empregando o IAC (índice de anomalia de chuva), assim como índice de aridez (IA), número de dias sem precipitação, precipitação acumulada, índice de vegetação da diferença normalizada (NVDI).

\section{Material e métodos}

\section{Área de estudo}

Foram utilizados postos pluviométricos situados no estado de Pernambuco, obtidos a partir dos dados da Agência Pernambucana de Águas e Clima (APAC, 2019). A escolha dos postos principais foi realizada de acordo com sua localização de forma a abranger da melhor forma o Estado de Pernambuco, para que pudesse ocorrer a sua devida caracterização. Os postos 
secundários foram escolhidos de forma que tivessem altitude semelhante aos postos principais devendo os mesmos serem próximos aos postos principais (Figura 2).

Outro fator importante relativo à escolha dos postos secundários foi $\mathrm{o}$ seu fator de correlação com os postos principais. Foi realizada a consistência de dados e o preenchimento de falhas entre 2000 a 2018 para os postos pluviométricos a partir do método vetor regional, tendo os coeficientes de correlação variando entre 0,6 a 0,89 . No total foram usados cerca de 131 postos de precipitação com o intuito de analisar o regime de chuvas no Estado de Pernambuco (Tabela 1 e Figura 3). A consistência dos dados foi realizada pelo método da dupla massa. O desvio de precipitação mensal entre 2000 a 2018 foi calculado a partir da diferença entre a média mensal entre 2000 a 2017 e a média mensal histórica para cada posto de precipitação. Os dados de temperatura de 2015 a 2018 foram obtidos a partir dos dados do Instituto Nacional de Meteorologia (INMET, 2019) (Tabela 2 e Figura 4) e foi utilizado o método de Thornthwaite (1948) para o cálculo da evapotranspiração potencial. Em relação os dados do Índice de Vegetação da Diferença Normalizada (NVDI) foram obtidos do Laboratório de Análise e Processamento de Imagens de Satélite (LAPIS, 2019).

Tabela 1. Postos pluviométricos com suas respectivas latitudes, longitudes e altitudes.

\begin{tabular}{|c|c|c|c|c|c|c|}
\hline Posto & Mesorregião & Entidade & Código & Latitude & Longitude & Altitude $(\mathrm{m})$ \\
\hline Abreu e lima & RMR & APAC & 198 & -7.9281 & -34.9 & 43 \\
\hline Igarassu & RMR & APAC & 100 & -7.8281 & -34.915 & 31 \\
\hline São Lourenço da Mata & RMR & APAC & 267 & -8.0403 & -35.1653 & 108 \\
\hline Paulista & RMR & APAC & 451 & -7.9428 & -34.8847 & 21 \\
\hline Camaragibe & RMR & APAC & 201 & -8.0217 & -34.9922 & 46 \\
\hline Jaboatão dos Guararapes & RMR & APAC & 268 & -8.1636 & -34.9228 & 12 \\
\hline Recife & RMR & APAC & 30 & -8.05 & -34.9167 & 10 \\
\hline Cabo & RMR & APAC & 490 & -8.2903 & -35.0294 & 31 \\
\hline Olinda & RMR & APAC & 199 & -7.99 & -34.85 & 08 \\
\hline Moreno & RMR & APAC & 205 & -8.1122 & -35.1003 & 122 \\
\hline Belo Jardim & $\mathrm{AP}$ & APAC & 20 & -8.3337 & -36.4253 & 611 \\
\hline B.M. Deus & $\mathrm{AP}$ & APAC & 113 & -8.1819 & -36.1942 & 475 \\
\hline Pesqueira & AP & APAC & 18 & -8.3531 & -36.6972 & 667 \\
\hline Sanharó & AP & APAC & 144 & -8.3639 & -36.5664 & 656 \\
\hline São Bento do Una & AP & APAC & 21 & -8.5272 & -36.4594 & 627 \\
\hline Bonito & $\mathrm{AP}$ & APAC & 469 & -8.4742 & -35.7836 & 451 \\
\hline Gravatá & AP & APAC & 58 & -8.2006 & -35.5431 & 496 \\
\hline Caruaru & $\mathrm{AP}$ & APAC & 24 & -8.2383 & -35.9158 & 653 \\
\hline Bezerros & AP & APAC & 67 & -8.2433 & -35.7528 & 488 \\
\hline São Caetano & AP & APAC & 122 & -8.3283 & -36.1375 & 557 \\
\hline Riacho das Almas & AP & APAC & 56 & -8.2006 & -35.5431 & 496 \\
\hline São Joaquim do Monte & AP & APAC & 123 & -8.8769 & -36.3667 & 714 \\
\hline Garanhuns & AP & APAC & 19 & -8.8833 & -36.4878 & 869 \\
\hline Brejão & AP & APAC & 443 & -9.0161 & -36.5356 & 704 \\
\hline Paranatama & AP & APAC & 154 & -8.9192 & -36.6583 & 867 \\
\hline Caetés & AP & APAC & 286 & -8.7728 & -36.6211 & 837 \\
\hline Capoeira & AP & APAC & 287 & -8.7342 & -36.6267 & 888 \\
\hline Jucati & AP & APAC & 157 & -8.7067 & -36.4928 & 841 \\
\hline Santa Cruz do Capibaribe & AP & APAC & 86 & -7.9533 & -36.2036 & 444 \\
\hline Toritama & AP & APAC & 70 & -8.0106 & -36.0564 & 347 \\
\hline Frei Miguelinho & AP & APAC & 218 & -7.9347 & -35.8469 & 395 \\
\hline Surubim & AP & APAC & 203 & -7.8369 & -35.7628 & 391 \\
\hline Vertentes & AP & APAC & 437 & -7.9047 & -35.9739 & 389 \\
\hline Bom Jardim & AP & APAC & 139 & -7.8017 & -35.5678 & 330 \\
\hline Vertente do Lírio & AP & APAC & 277 & -7.775 & -35.8497 & 444 \\
\hline Joao Alfredo & AP & APAC & 523 & -7.8539 & -35.5886 & 383 \\
\hline Afogados do Ingazeira & SP & APAC & 290 & -7.7569 & -37.6331 & 541 \\
\hline Carnaíba & SP & APAC & 184 & -7.8078 & -37.7981 & 489 \\
\hline Iguaraci & SP & APAC & 148 & -7.8325 & -37.5128 & 565 \\
\hline
\end{tabular}


Revista Brasileira de Geografia Física v.13, n.01 (2020) 001-017

\begin{tabular}{|c|c|c|c|c|c|c|}
\hline Flores & SP & APAC & 183 & -7.8669 & -37.9739 & 465 \\
\hline São Jose do Egito & SP & APAC & 92 & -7.4444 & -37.2806 & 659 \\
\hline Arcoverde & SP & APAC & 16 & -8.4336 & -37.0556 & 687 \\
\hline Alagoinha & SP & APAC & 140 & -8.4661 & -36.7739 & 730 \\
\hline Buíque & SP & APAC & 145 & -8.6147 & -37.1547 & 837 \\
\hline Pedra & SP & APAC & 208 & -8.8625 & -36.9428 & 433 \\
\hline Pesqueira & SP & APAC & 18 & -8.3531 & -36.6972 & 667 \\
\hline Sertânia & SP & APAC & 185 & -8.075 & -37.2639 & 551 \\
\hline Betânia & SP & APAC & 93 & -8.2708 & -38.0331 & 439 \\
\hline Serra Talhada & SP & APAC & 13 & -7.9306 & -38.2886 & 513 \\
\hline Custodia & SP & APAC & 147 & -8.0864 & -37.645 & 539 \\
\hline Floresta & SP & APAC & 32 & -8.6167 & -38.5667 & 325 \\
\hline Ibimirim & SP & APAC & 14 & -8.5978 & -37.6786 & 394 \\
\hline Carnaubeira da Penha & SP & APAC & 288 & -8.3222 & -38.7403 & 453 \\
\hline Bodocó & SP & APAC & 50 & -7.7806 & -39.9375 & 442 \\
\hline Ipubi & SP & APAC & 84 & -7.6522 & -40.1469 & 544 \\
\hline Exu & SP & APAC & 51 & -7.5161 & -39.7294 & 525 \\
\hline Ouricuri & SP & APAC & 175 & -7.8525 & -40.3389 & 494 \\
\hline Parnamirim & SP & APAC & 172 & -8.0889 & -39.5775 & 392 \\
\hline Moreilândia & SP & APAC & 81 & -7.6075 & -39.55 & 552 \\
\hline Brejinho & SP & APAC & 473 & -7.3478 & -37.2847 & 737 \\
\hline Santa Terezinha & SP & APAC & 471 & -7.3747 & -37.4997 & 832 \\
\hline Itapetim & SP & APAC & 155 & -7.3767 & -37.2006 & 635 \\
\hline Inajá (CHESF) & SP & APAC & 33 & -8.9 & -37.8167 & 361 \\
\hline Tupanatinga & SP & APAC & 141 & -8.7547 & -37.3422 & 713 \\
\hline Salgueiro & SP & APAC & 8 & -8.0733 & -39.1297 & 444 \\
\hline Terra Nova & SP & APAC & 179 & -8.2272 & -39.3772 & 373 \\
\hline Mirandiba & SP & APAC & 54 & -8.1158 & -38.7272 & 438 \\
\hline Serrita (Cartório) & SP & APAC & 180 & -7.9447 & -39.2931 & 423 \\
\hline Verdejante & SP & APAC & 181 & -7.9286 & -38.9694 & 505 \\
\hline Calumbi & SP & APAC & 91 & -7.9394 & -38.1539 & 451 \\
\hline $\begin{array}{l}\text { Santa Cruz da Baixa } \\
\text { Verde }\end{array}$ & SP & APAC & 336 & -7.8203 & -38.1511 & 855 \\
\hline Triunfo & SP & APAC & 182 & -7.8372 & -38.1061 & 1059 \\
\hline Araripina & SP & APAC & 3 & -7.5767 & -40.5058 & 636 \\
\hline Santa Cruz da Venerada & SP & APAC & 164 & -8.2406 & -40.3369 & 513 \\
\hline Solidão & SP & APAC & 357 & -7.6007 & -37.6581 & 695 \\
\hline Tuparetama & SP & APAC & 529 & -7.6867 & -37.2214 & 604 \\
\hline
\end{tabular}

Fonte: Autores (2019).

Tabela 2. Postos de temperatura com suas respectivas latitudes, longitudes e altitudes.

\begin{tabular}{lcccccc}
\hline Posto & Mesorregião & Entidade & Código & Latitude & Longitude & Altitude \\
\hline Arcoverde - A309 & SP & INMET & 81953 & -8.434 & -37.055 & 684 \\
Caruaru - A341 & AP & INMET & 81956 & -8.236 & -35.986 & 570 \\
Ibimirim - A349 & SP & INMET & 81954 & -8.510 & -37.712 & 434 \\
Ouricuri - A366 & SP & INMET & 81910 & -7.886 & -40.103 & 458 \\
Palmares- A357 & MP & INMET & 81957 & -8.667 & -35.568 & 164 \\
Recife- A301 & RMR & INMET & 81958 & -8.059 & -34.959 & 11 \\
Salgueiro-A370 & SP & INMET & 81949 & -8.058 & -39.096 & 447 \\
Serra Talhada- A350 & SP & INMET & 81912 & -7.954 & -38.295 & 499 \\
Surubim - A328 & AP & INMET & 81917 & -7.840 & -35.801 & 421 \\
São Luís do Quitunde & AL & INMET & 81997 & -9.287 & -35.566 & 14 \\
Garanhuns-A322 & AP & INMET & 81955 & -8.911 & -36.493 & 828 \\
\hline
\end{tabular}

Fonte: Autores (2019). 


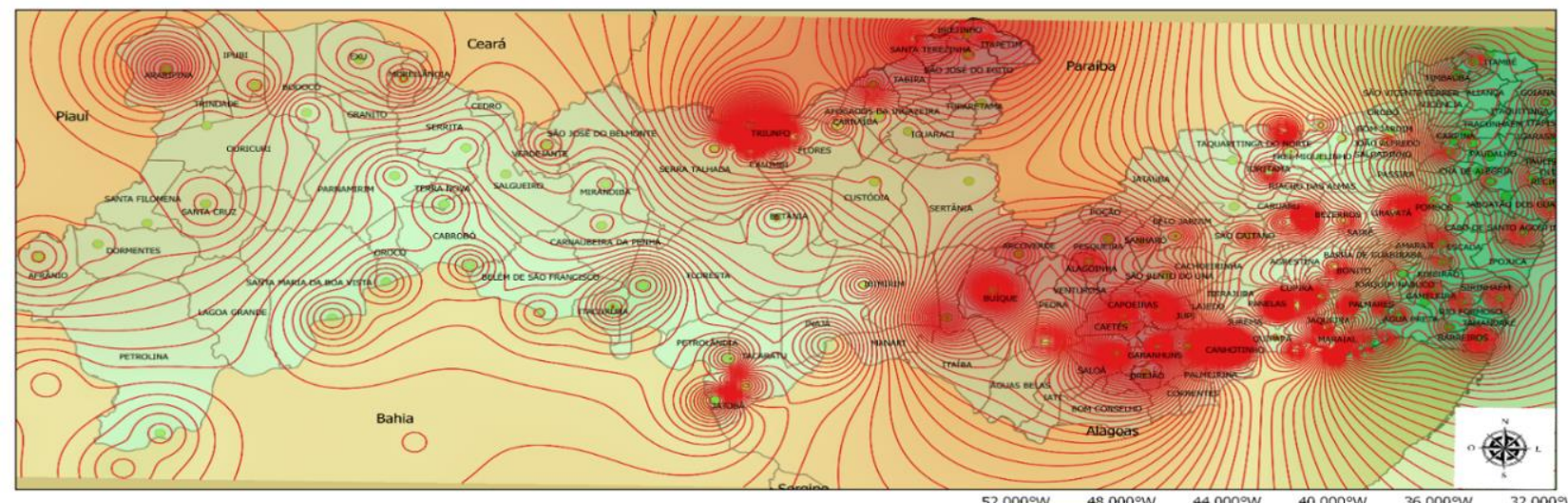

\section{Legenda}

\section{- Curvas de nivel}

Interpolação das Altitude pelo Metodo IDW

140

$\square 275$

$\begin{array}{r}\square 09 \\ \square \quad 544 \\ \hline\end{array}$

544
679

$\square$ Regioes do Brasil

$\square$ Regiao Nordeste

- Postos Pluviometricos

$\square$ Estado de Pernambuco
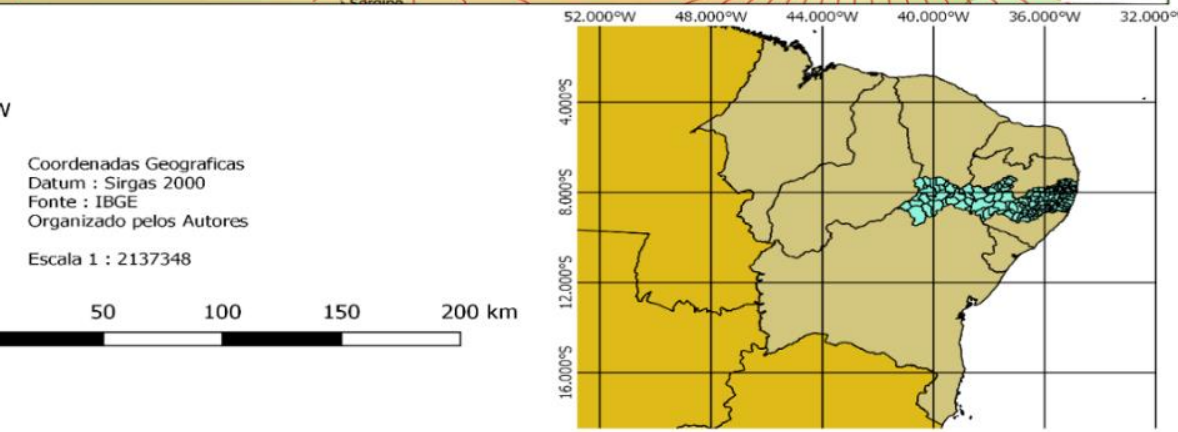

Figura 2. Curva de nível dos postos de estudo. Fonte: Autores (2019).

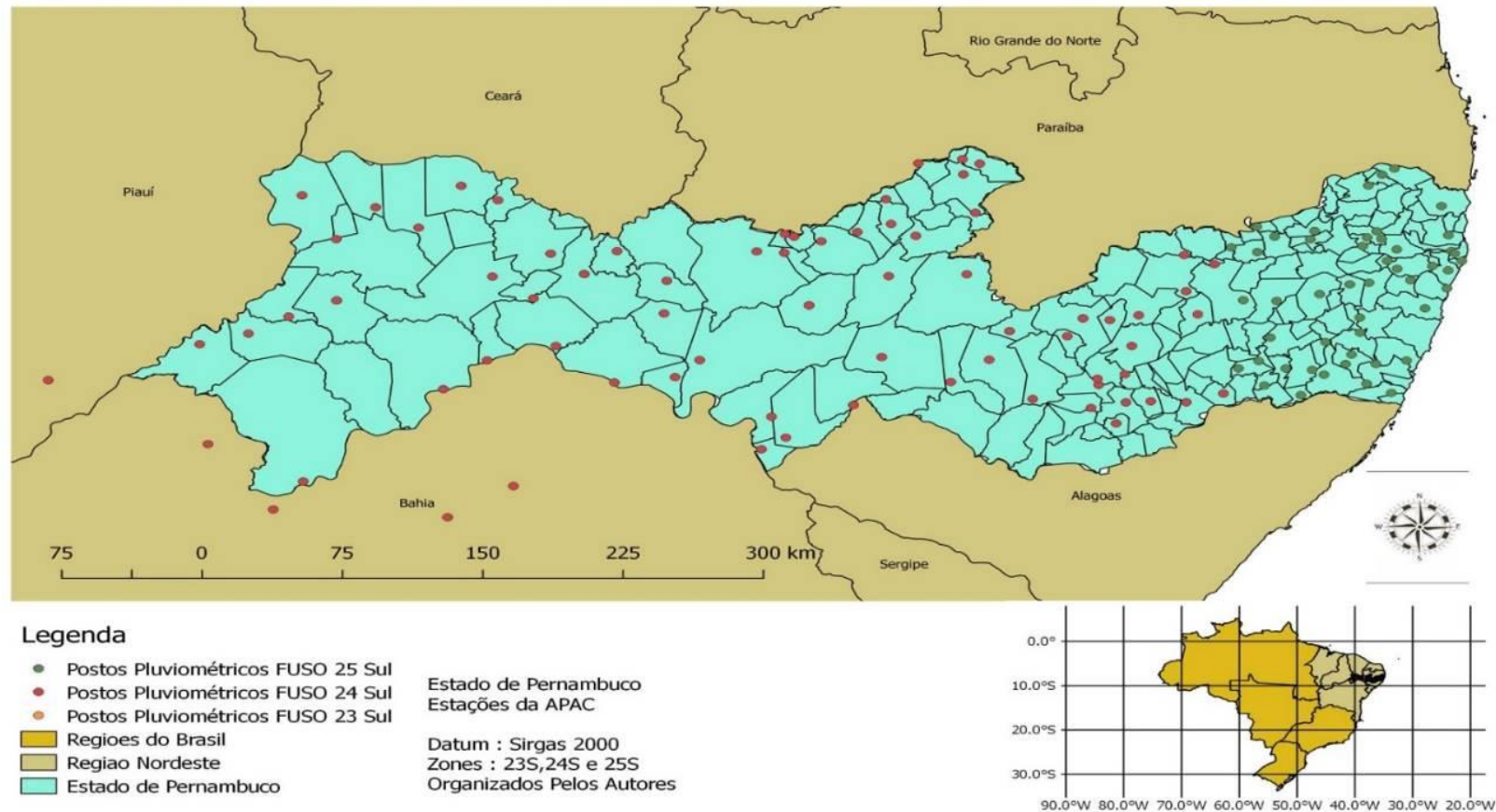

Figura 3. Postos pluviométricos de estudo. Fonte: Autores (2019). 

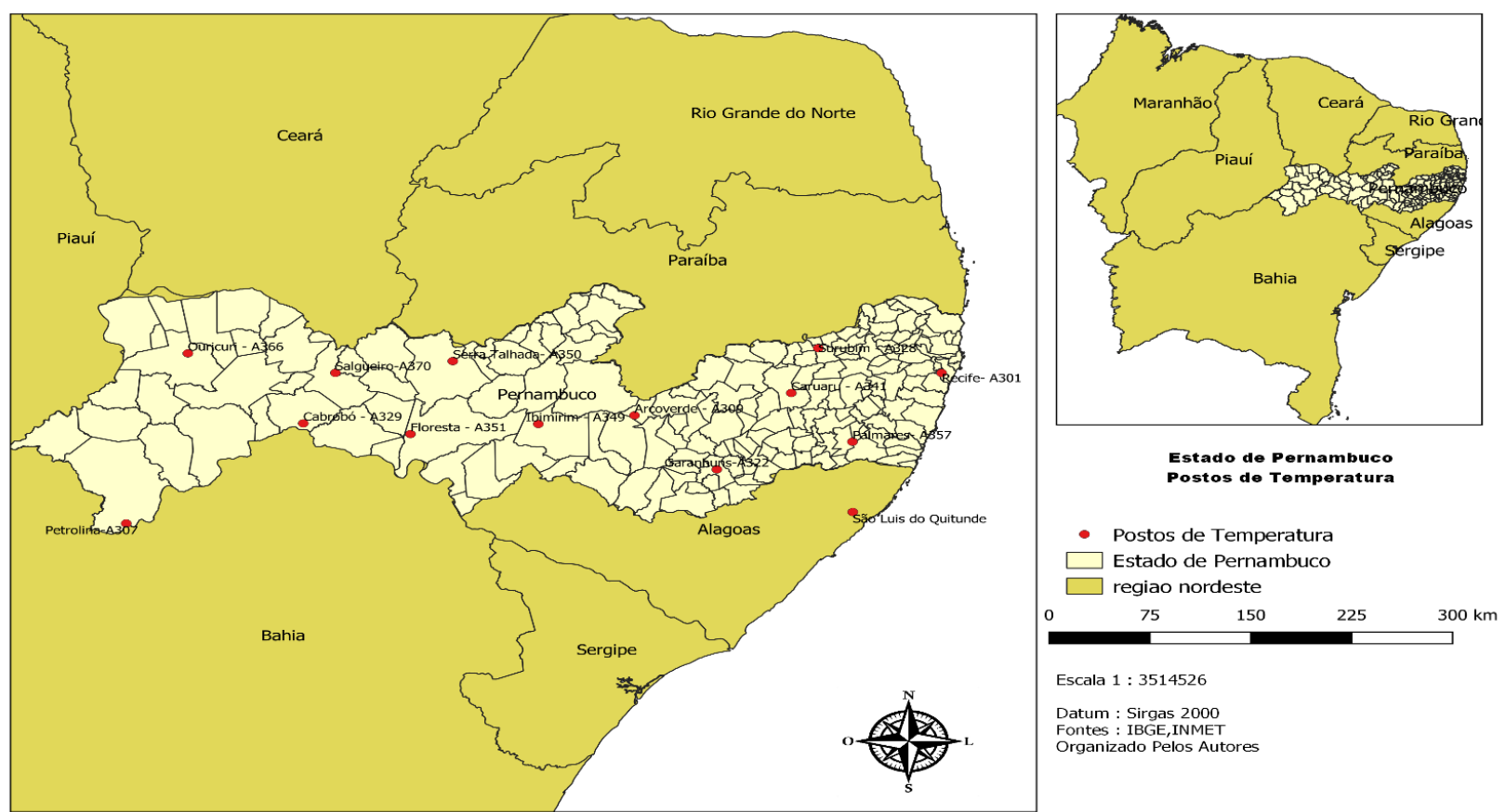

Figura 4. Postos de temperatura utilizados no estudo. Fonte: Autores (2019).

\section{Estudo da variabilidade pluviométrica}

Inicialmente, procedeu-se ao processo de correlação dos dados de precipitação média mensal dos postos pluviométricos situados próximos aos postos principais onde apresentaram boa correlação. Após a correlação dos dados, foi observada a variação da precipitação média anual e calculado o desvio de precipitação mensal. Os postos principais foram:

\section{Mesorregião: Região Metropolitana do Recife \\ Recife \\ Jaboatão dos Guararapes \\ Mesorregião: Agreste Pernambucano

$\begin{array}{lr}\text { Bezerros } & \text { Santa Cruz do Capibaribe } \\ \text { Belo Jardim } & \text { Surubim } \\ \text { Caruaru } & \text { Garanhuns }\end{array}$ \\ Mesorregião: Sertão Pernambucano}

Afogados do Ingazeira

Arcoverde

Betânia

Serra Talhada

Bodocó

Ibimirim

Brejinho

Salgueiro

Exú

Ouricuri

\section{Tendência da precipitação pluviométrica}

Para analisar a tendência da precipitação foi utilizado o software Trend. A partir dos resultados do Trend, para os postos que apresentaram tendência foram realizados o cálculo da regressão linear sobre os dados de precipitação utilizando o software BioEstat.

\section{Resultados e discussão}

Análise da variabilidade pluviométrica

Mesorregião: Região Metropolitana do Recife

Na Mesorregião da Região Metropolitana do Recife, os postos de estudos apresentaram um comportamento pluviométrico próximos com pequena assimetria nos dados, como pode ser observado na Figura 5. O coeficiente de correlação ficou entre 0,72 a 0,87 , enquanto o coeficiente de determinação ficou entre 0,8 a 0,9 . Os menores valores de precipitação encontrados, entre 2000 a 2018, foram nos anos de 2003, 2006, 2010 e 2012, sendo o menor valor encontrado no ano de 2018 no município de Abreu e Lima. Enquanto os maiores valores de precipitação foram nos anos de 2000, 2004 e 2011 onde o maior valor foi encontrado no ano de 2000 no município de Recife. Em relação a precipitação diária, foi observado que os municípios de Recife e Camaragibe apresentaram os maiores valores em relação a precipitação diária acumulada entre 2000 e 2018, enquanto os municípios de Abreu e Lima e Jaboatão dos Guararapes apresentaram as maiores quantidades de dias sem precipitação entre 2000 e 2018. A maior precipitação observada foi nos municípios de Camaragibe e Recife. A precipitação média diária de Recife e Camaragibe apresentaram tendência de queda. 


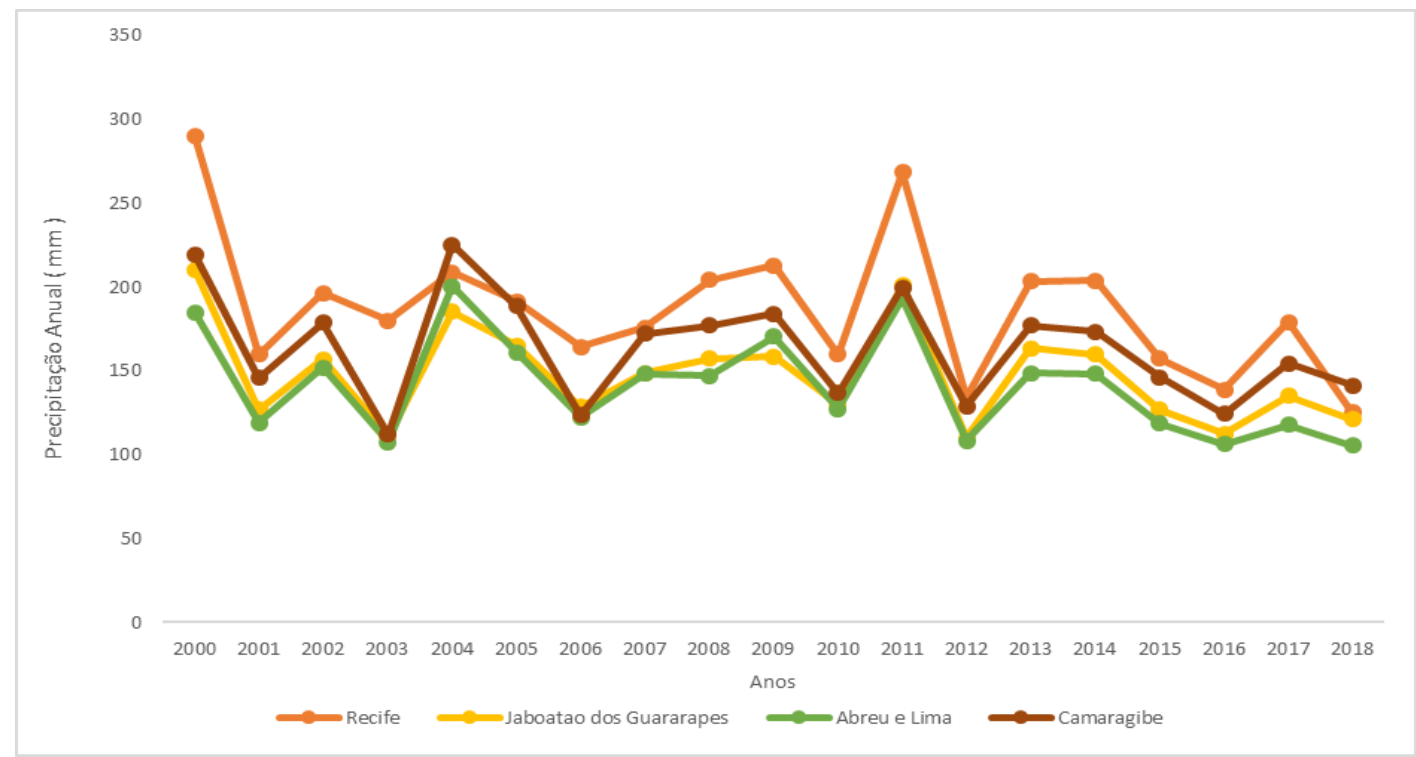

Figura 5. Variabilidade pluviométrica da Região Metropolitana do Recife. Fonte: Autores (2019).

\section{Mesorregião: Agreste Pernambucano}

$\mathrm{Na}$ Mesorregião da Região Agreste Pernambucano, os postos de estudos apresentaram um comportamento pluviométrico diferentes em alguns locais, como pode ser observado na Figura 6. Isto pode ser explicado devido a variação da topografia na região. Os menores valores de precipitação observados entre os anos de 2000 a 2018, foram nos anos de 2001, 2003,2007 e 2012, sendo observado o menor valor no ano de 2012 no município de caruaru enquanto que os maiores valores de precipitação foram nos anos de 2002, 2004, 2009 e 2010, onde o maior valor foi encontrado no ano de 2010 no município de belo Jardim. Em relação ao número de dias sem precipitação, os municípios de Belo Jardim, Surubim e Santa Cruz do Capibaribe apresentaram os maiores valores, sendo o município de Santa Cruz do Capibaribe o que apresentou a maior quantidade de dias sem precipitação. Analisando a precipitação diária acumulada entre 2000 e 2018, o município de caruaru apresentou o maior Valor. Em relação a precipitação média diária, os municípios de Caruaru e Santa Cruz do Capibaribe apresentaram tendência de queda. Os municípios de Belo Jardim e Bezerros apresentaram tendência de queda, enquanto o município de caruaru apresentou tendência de aumento

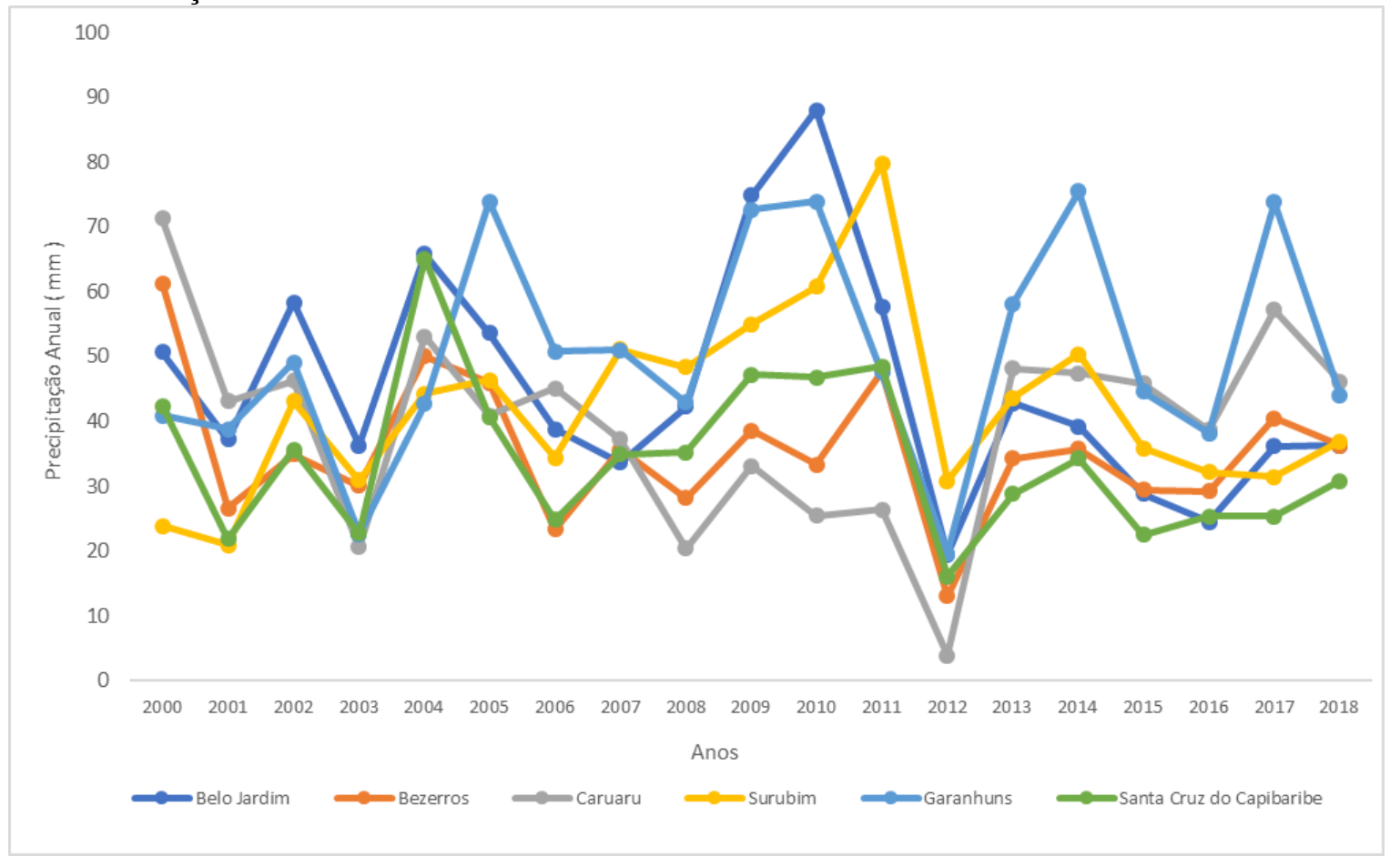

Figura 6. Variabilidade pluviométrica do Agreste Pernambucano. Fonte: Autores (2019). 


\section{Mesorregião: Sertão Pernambucana}

Na Mesorregião da Região do Sertão Pernambucano, os postos de estudos apresentaram um comportamento pluviométrico próximos com pequena assimetria nos dados, como pode ser observado na Figura 7. Os menores valores de precipitação encontrados, entre 2000 a 2018, foram nos anos de 2001, 2003, 2005, 2007, 2009, 2010, 2012, 2015 e 2017, sendo o município de Betânia, no ano de 2012, o município que apresentou o menor valor de precipitação, enquanto que os maiores valores de precipitação foram nos anos de 2002, 2004, 2006, 2008, 2011, 2014 e 2018, sendo o município de Brejinho, no ano de 2009, o município que apresentou o maior valor de precipitação. Os municípios de Bodocó e Betânia apresentaram as maiores quantidades de dias sem precipitação entre 2000 a 2018, enquanto os municípios de Arcoverde, Afogados da Ingazeira, Brejinho e Serra Talhada apresentaram os maiores valores de precipitação diária acumulada entre 2000 a 2018, sendo o município de Brejinho aquele que apresentou o maior valor. Os municípios de Bodocó, Ibimirim e Ouricuri apresentaram tendência de queda para a precipitação média diária, enquanto o município de Serra Talhada apresentou tendência de aumento. Serra Talhada também apresentou tendência de queda na quantidade de dias sem precipitação.

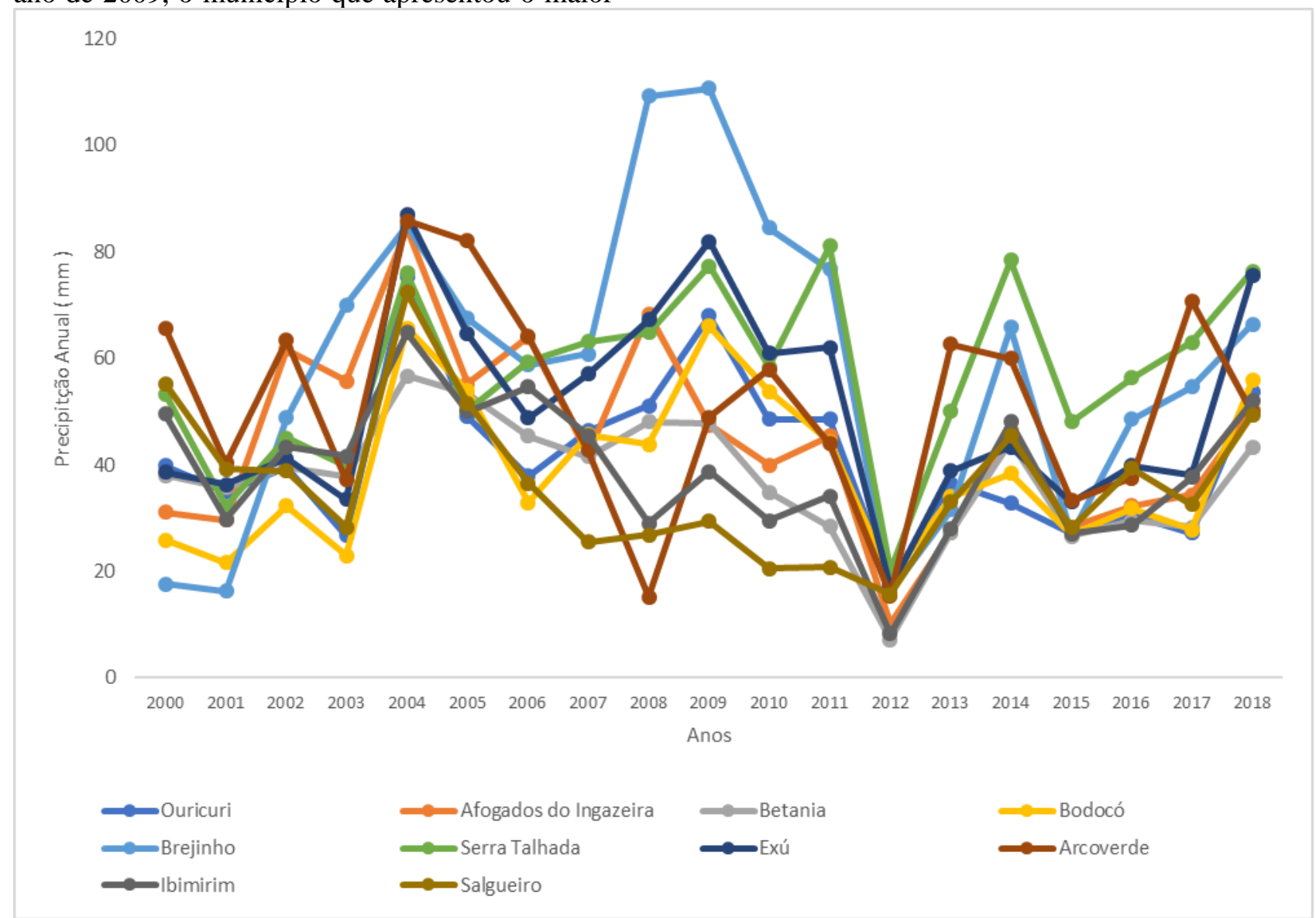

Figura 7. Variabilidade pluviométrica da região do Sertão Pernambucano. Fonte: Autores (2019).

\section{Precipitação diária acumulada entre 2000 e 2018}

Analisando a Figura 8, observa-se que os menores valores de precipitação diária acumulada, entre 2000 a 2018, localizam-se, principalmente, na região do São Francisco e no Sertão Pernambucano, sendo o município de Cabrobó aquele que apresentou o menor valor. Entre os municípios que apresentaram precipitação diária acumulada menor que 16000 mm foram Afrânio,
Ouricuri, Ibimirim, Brejinho, Exú, Afogados da ingazeira, Dormentes, Petrolina, Floresta, Cabrobó, Belém de São Francisco, Ferreiros, Surubim, Santa Cruz do Capibaribe e Bezerros. Os municípios que apresentaram os maiores valores de precipitação diária acumulada foram: Recife, Camaragibe, Jaboatão dos Guararapes, Abreu e lima, Gameleira, Vitoria de Santo Antão, Palmares, Igarassu, Olinda, Itapissuma e Paulista. 


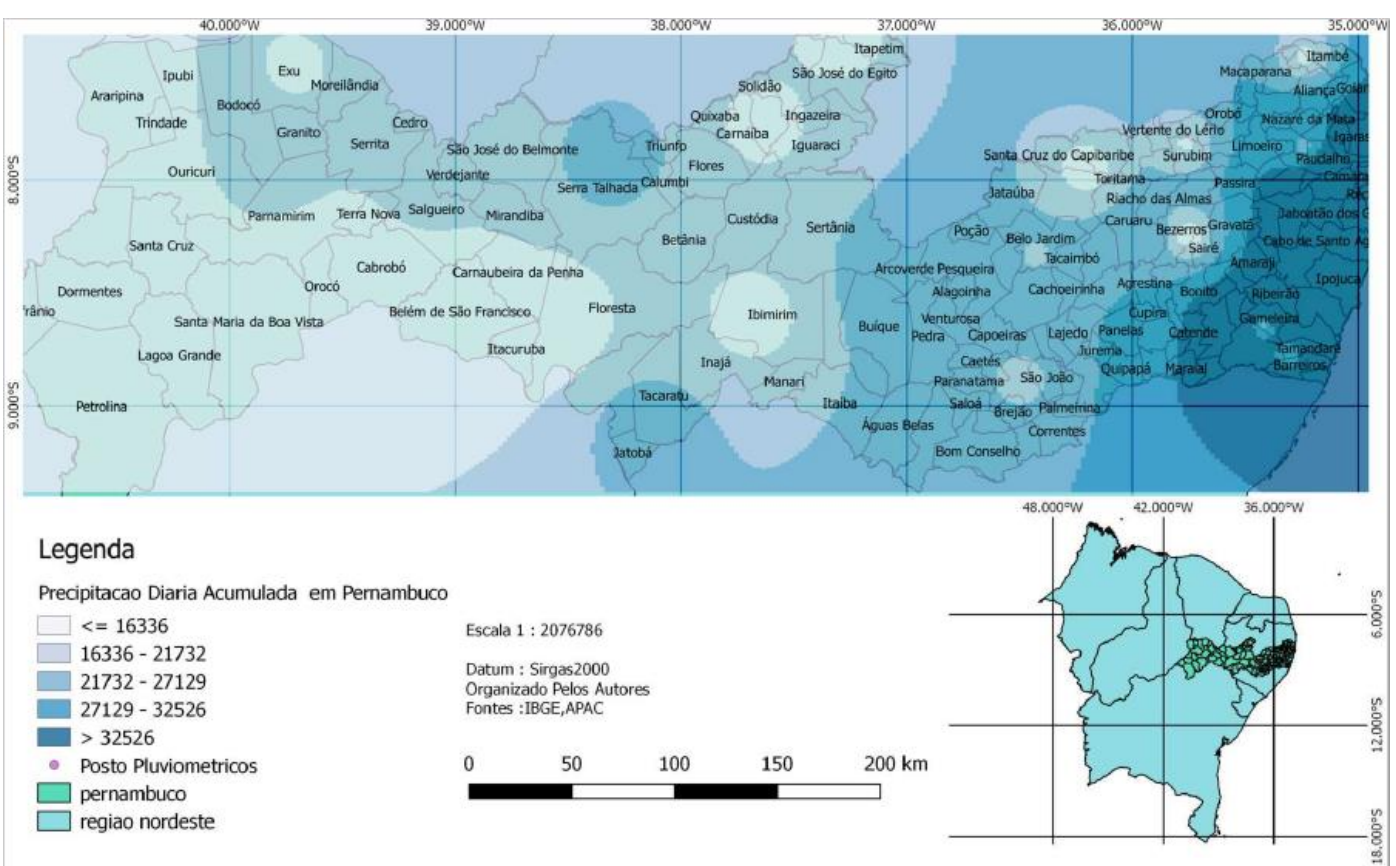

Figura 8. Precipitação diária acumulada entre 2000 - 2018 no Estado de Pernambuco. Fonte: Autores (2019).

Índice de anomalia de chuvas anual (IAC)

\section{Mesorregião: Região Metropolitana do Recife}

Analisando os resultados do índice de anomalia de chuvas anual, Figura 9, observa-se que todos os municípios apresentaram em sua maioria períodos chuvosos e muito chuvosos. Os municípios apresentaram período de seca no ano de 2012. Os municípios de Camaragibe, Abreu e Lima e Jaboatão dos Guararapes apresentaram

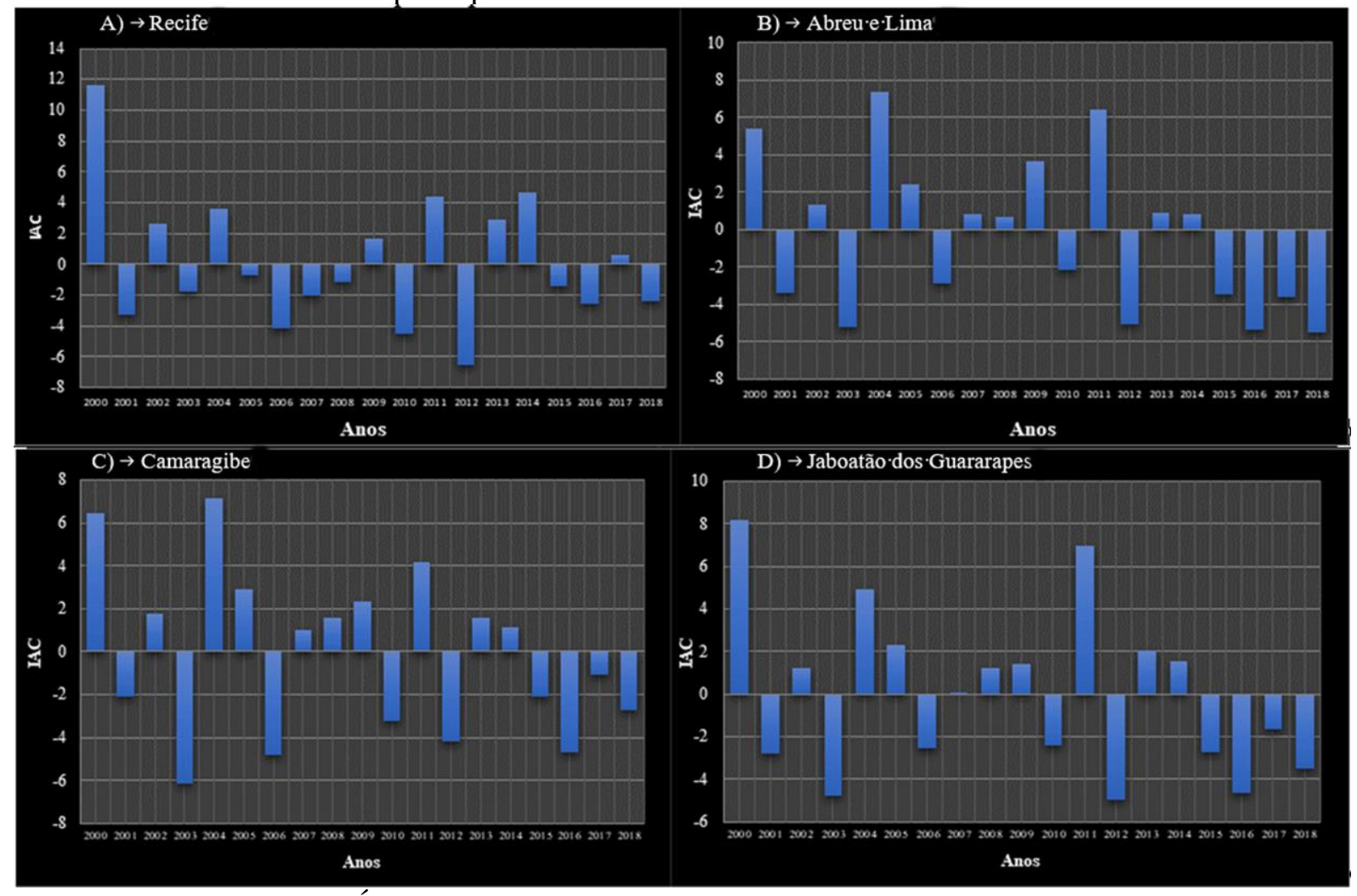

Figura 9. Índice de anomalia de chuvas anual. Fonte: Autores (2019). períodos de seca consecutivos entre os anos de 2015 a 2018, sendo o município de Abreu e Lima aquele que apresentou a seca mais forte no mês de novembro de 2017. O município de Abreu e Lima apresentou a maior quantidade de meses com períodos de seca, entre os meses de junho de 2016 a junho de 2017. Para o município de Abreu e Lima, o índice de anomalia de chuvas apresentou tendência de queda. 


\section{Mesorregião: Agreste Pernambucano}

Em relação ao índice de anomalia de chuvas anual, Figura 10, tem-se que a maioria dos municípios apresentaram maiores períodos de seca, enquanto os municípios de Caruaru, Garanhuns e Surubim apresentaram maiores quantidades de períodos chuvosos. Todos os
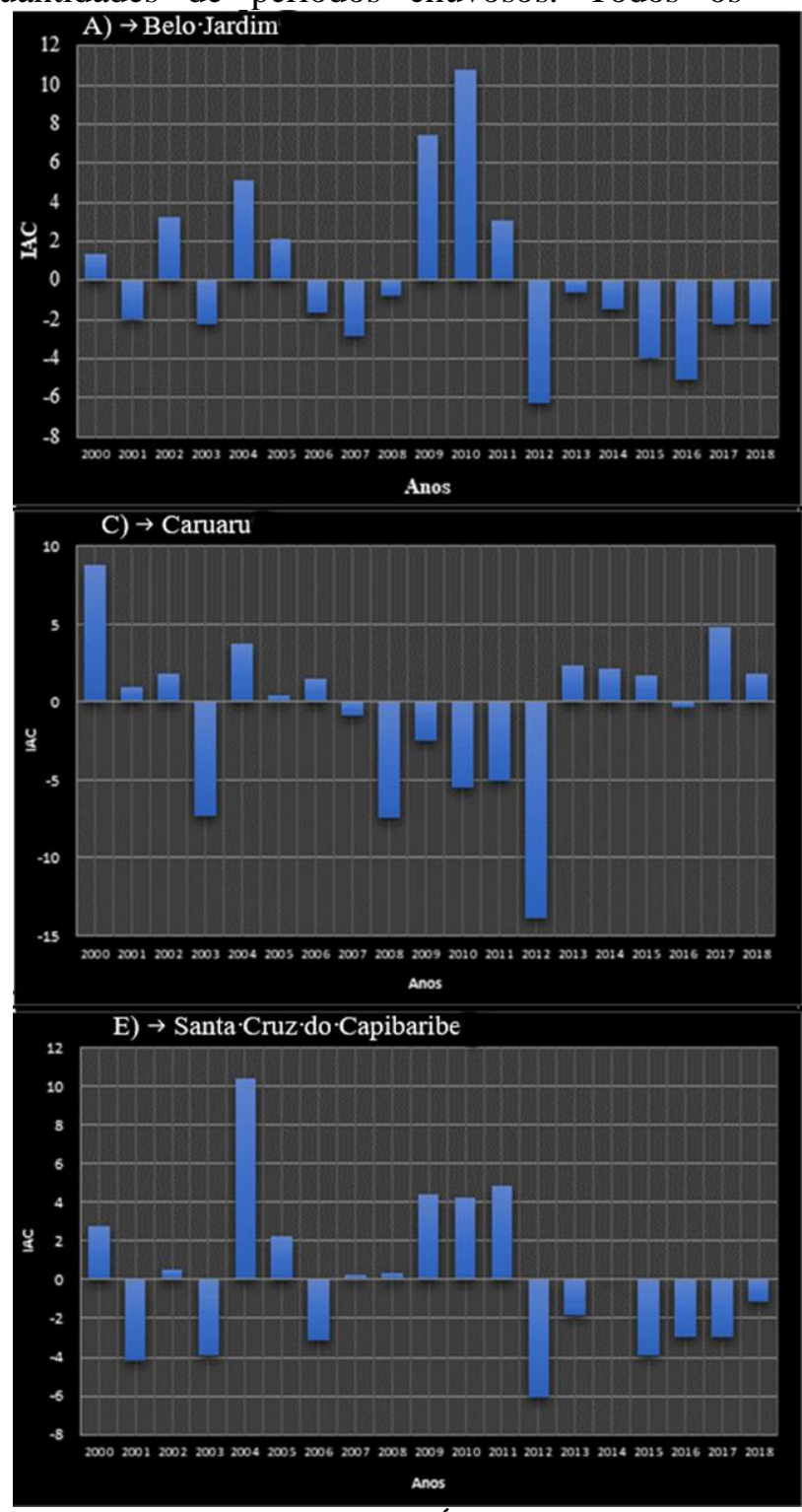

Figura 10. Índice de anomalia de chuvas anual. Fonte: Autores (2019).

\section{Mesorregião: Sertão Pernambucano}

Para a região do sertão Pernambucano, o índice de anomalia de chuvas anual, Figuras $11 \mathrm{e}$ 12, variaram entre $-11,11 \mathrm{a}+9,78$, onde os municípios de Bodocó, Exu, Ouricuri e Ibimirim apresentaram maiores períodos de seca consecutivos entre 2015 a 2018. Todos os municípios apresentaram períodos de seca nos anos 2012, 2015, 2016 e 2017, em especial no ano municípios apresentaram períodos de seca nos anos de 2001, 2003, 2012 e 2016. Os municípios de Belo jardim e Santa Cruz do Capibaribe apresentaram as maiores quantidades meses secos, sendo o município de Bezerros aquele que apresentou a seca mais forte, no mês de novembro de 2015.
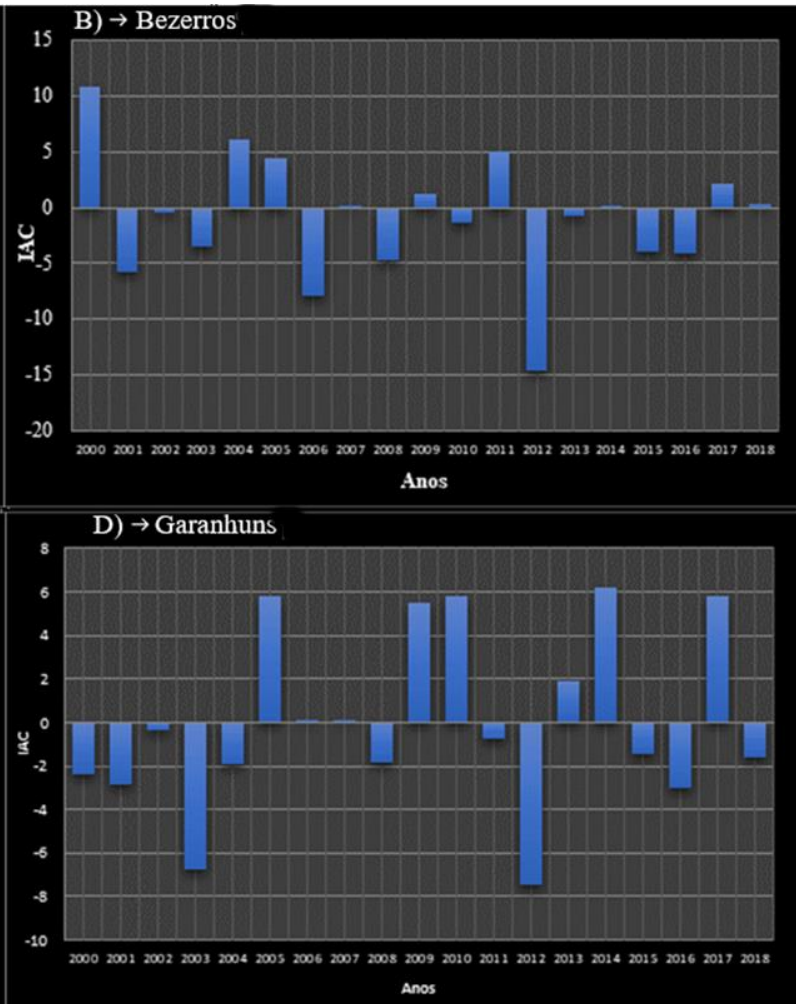

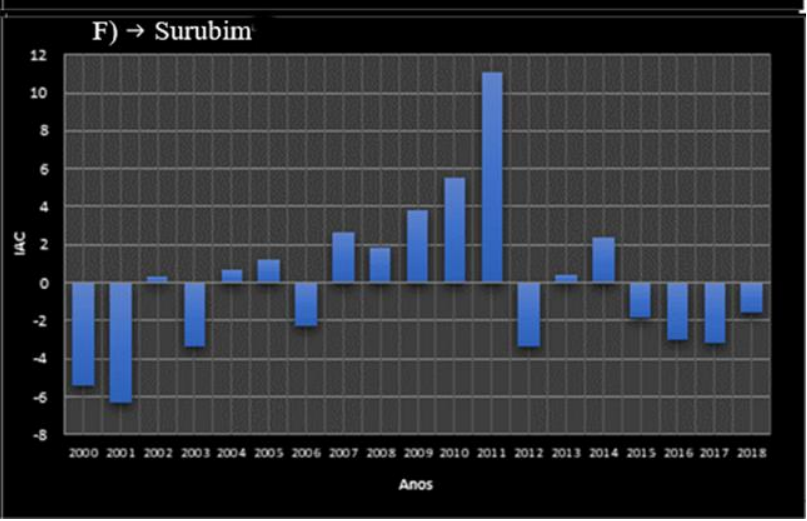

de 2012, onde a maioria dos municípios apresentou período de seca forte devido à seca. $\mathrm{O}$ período de seca mais severo ocorreu no município de Betânia, em 2012. Os municípios de Afogados da Ingazeira, Betânia e Brejinho apresentaram as maiores quantidades de períodos chuvosos. Os municípios de Betânia e Ibimirim apresentaram tendência de queda para o índice de anomalia de chuvas. 


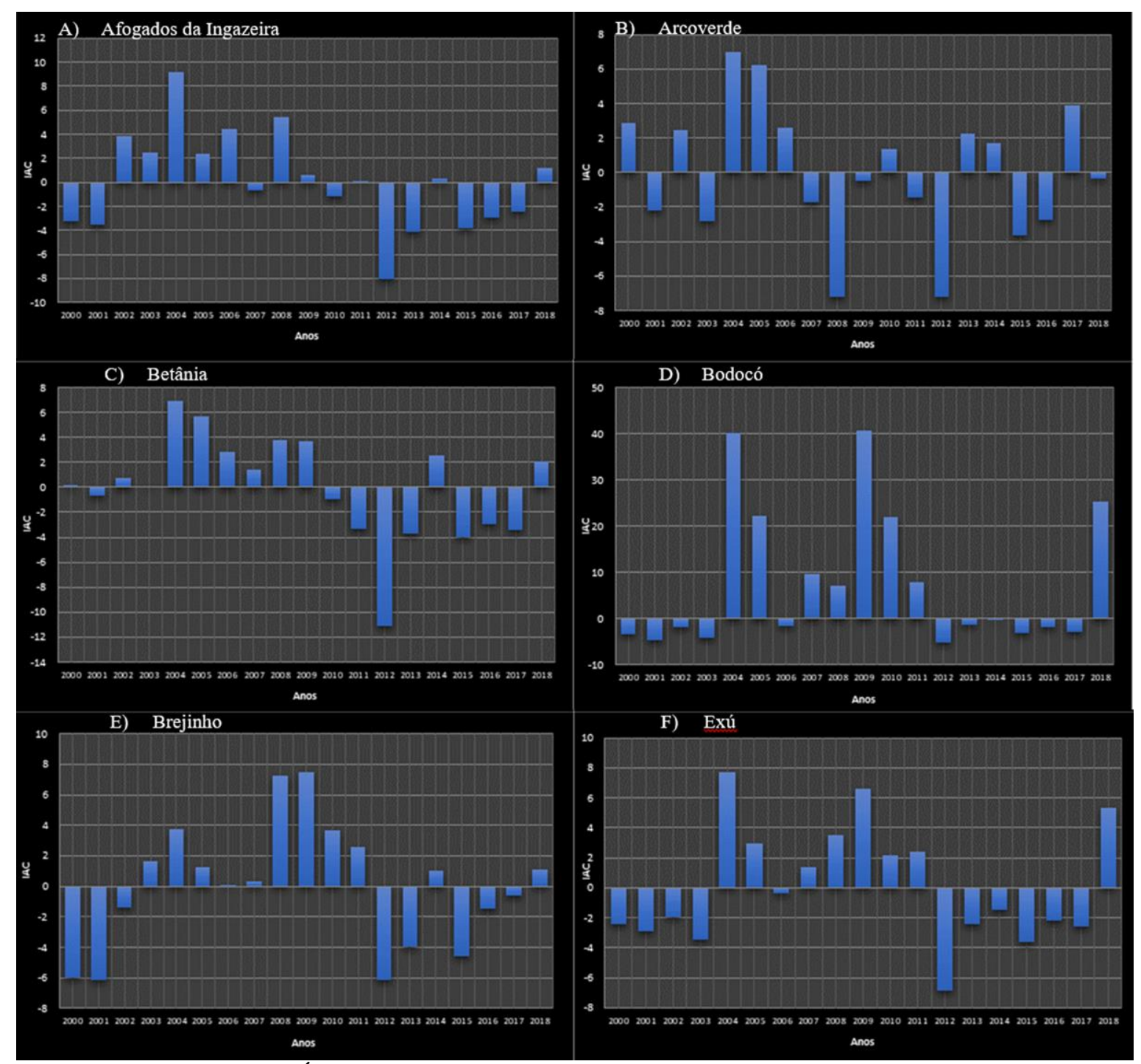

Figura 11. Índice de anomalia de chuvas anual. Fonte: Autores (2019).
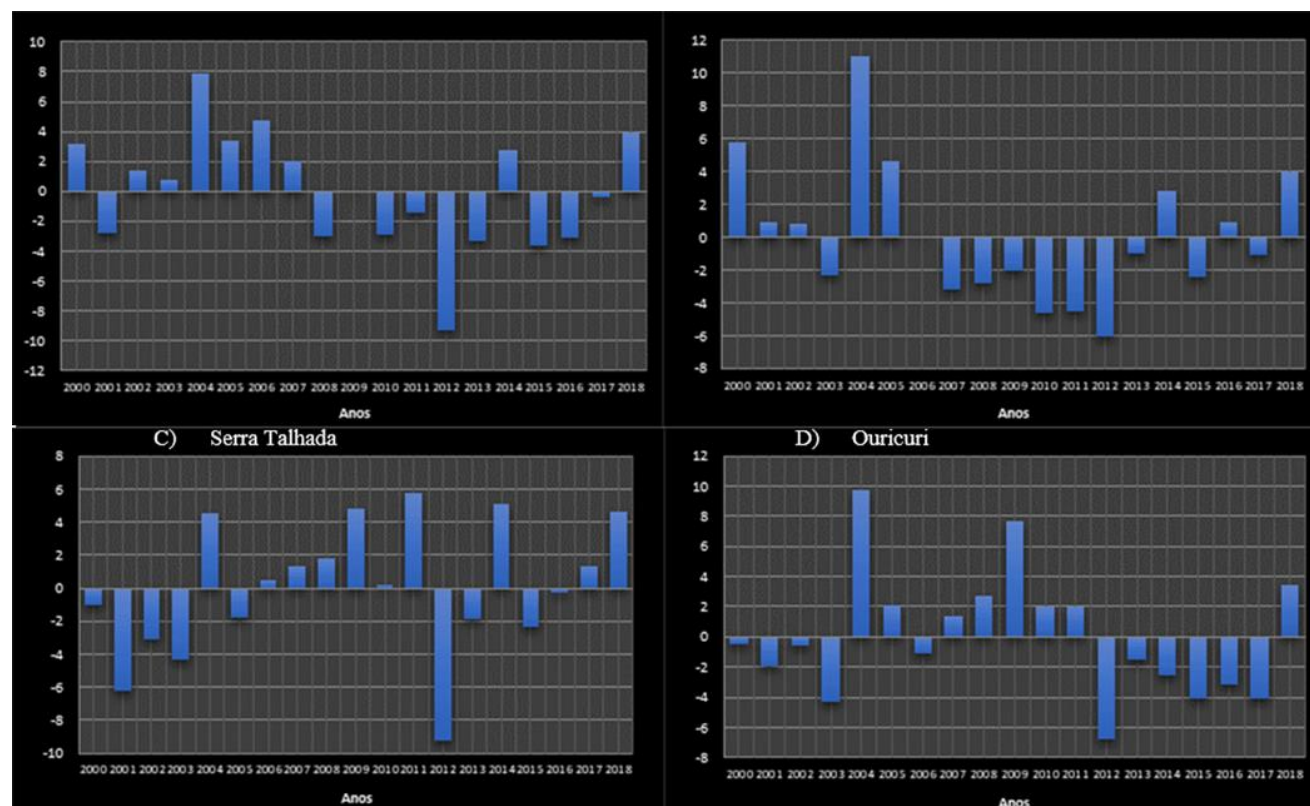

Figura 12. Índice de anomalia de chuvas anual. Fonte: Autores (2019). 
Índice de aridez anual (IA)

\section{Mesorregião: Região Metropolitana do Recife}

A partir dos cálculos do índice de aridez, Figura 13, foi observado que os municípios da região Metropolitana do Recife apresentaram zona climática Subúmido e úmido entre 2015 a 2018, onde os municípios apresentaram um comportamento bastante homogêneo entre si, onde os municípios de Abreu e Lima e Jaboatão dos Guararapes tiveram um índice de aridez muito semelhante. Não houve uma diferença significativa nas temperaturas média anual dos municípios de região, sendo $26,125{ }^{\circ} \mathrm{C}$ a média das temperaturas observadas. As menores temperaturas foram observadas no mês de julho e agosto entre 2015 a 2018, enquanto que as maiores temperaturas foram observadas no ano de 2017 nos meses de janeiro, fevereiro, março, abril, maio e dezembro, chegando a temperatura média de $28,15^{\circ} \mathrm{C}$.

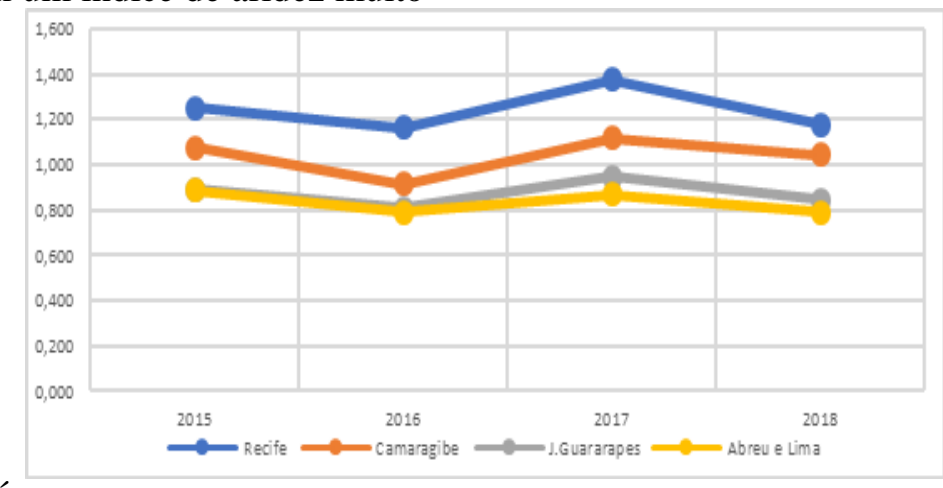

Figura 13. Índice de aridez da região Metropolitana do Recife. Fonte: Autores (2019).

Mesorregião: Agreste Pernambucano

A Partir dos cálculos do índice de aridez, foi observado que os municípios do Agreste Pernambucano, apresentaram zonas climáticas áridas, semiáridas e Subúmidas, sendo a Zona semiárida a classe climática de maior presença, onde os municípios de Bezerros e Belo Jardim apresentaram um comportamento bastante homogêneo entre si, como pode ser observado na Figura 14. Os municípios de Garanhuns e caruaru apresentaram os maiores valores, enquanto que o município de Santa Cruz do Capibaribe apresentou índice de aridez com valores de 0,17. As menores Temperaturas foram observadas no mês de julho de 2017, onde a menor temperatura média foi de $18,55{ }^{\circ} \mathrm{C}$, no município de Garanhuns, enquanto que as maiores temperaturas foram observadas no mês de dezembro de 2017, no município de Santa Cruz do Capibaribe e Surubim.

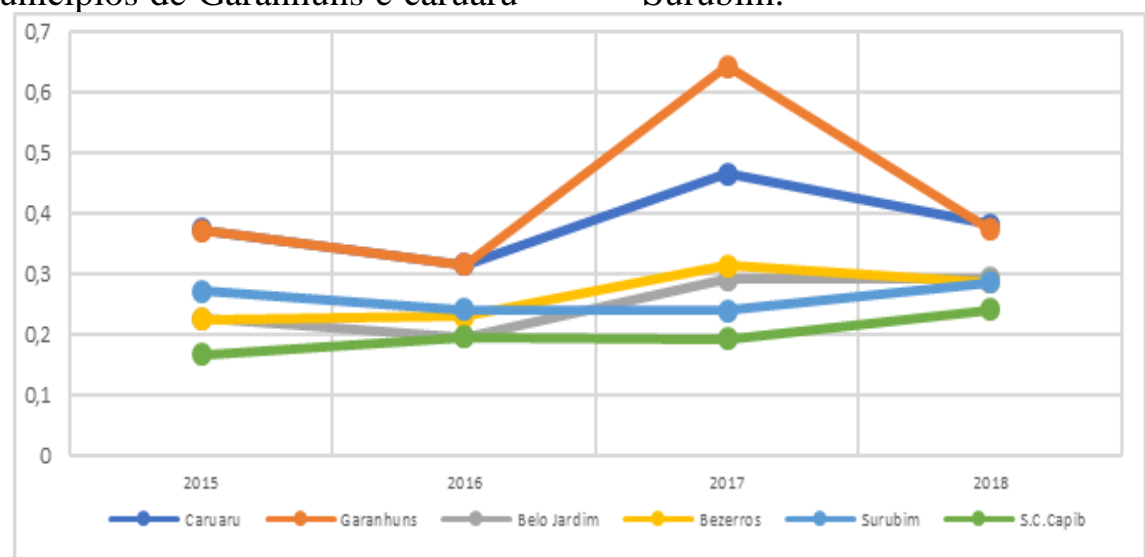

Figura 14. Índice de aridez do Agreste Pernambucana. Fonte: Autores (2019).

Mesorregião: Sertão Pernambucano

A Partir dos cálculos do índice de aridez, foi observado que os municípios da Sertão Pernambucano apresentaram zona climática Arida e Semiárida entre 2015 a 2018, onde a maior parte dos municípios apresentaram um comportamento semelhante, exceto o município de Arcoverde e Brejinho, como pode ser observado na Figura 15.
O índice de aridez variou entre 0,189 a 0,572, onde o município de Arcoverde apresentou o maior valor enquanto que o município de Ouricuri apresentou os menores. A menor temperatura média observada entre 2015 a 2018 foi de 18,55 ${ }^{\circ} \mathrm{C}$ pelo município de Ibimirim enquanto que a maior temperatura observada foi de $30,75^{\circ} \mathrm{C}$ obtida pelo município de Ouricuri. 


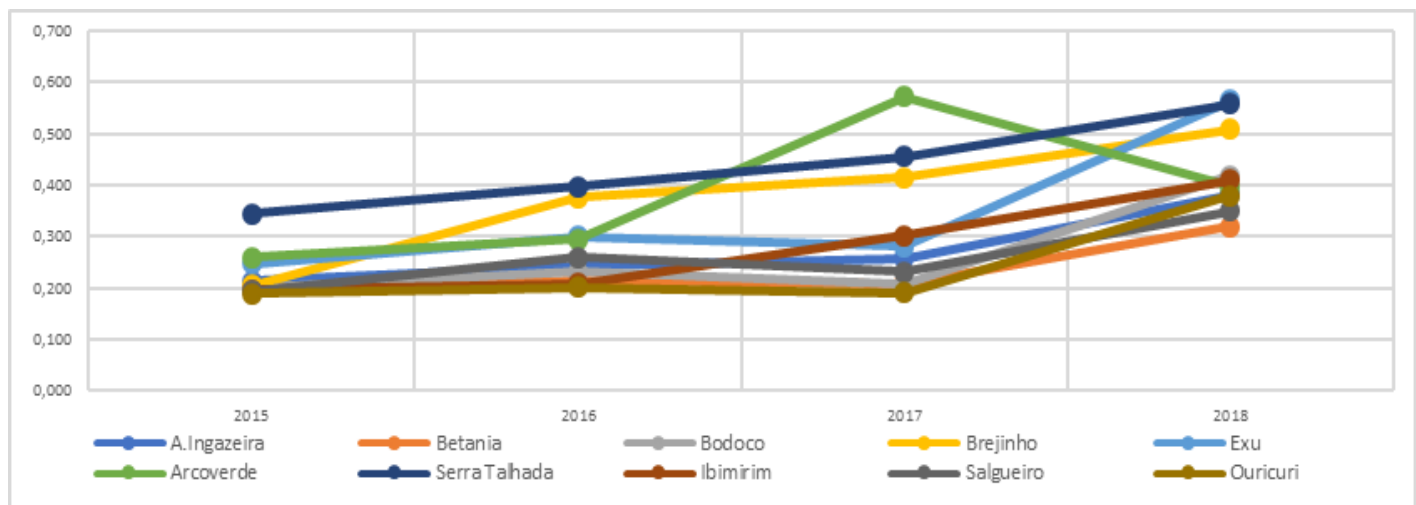

Figura 15. Índice de aridez do Sertão Pernambucano. Fonte: Autores (2019).

NVDI do Estado de Pernambuco nos anos de 2007 e 2016.

Segundo o diagnóstico da Seca 2011-2016 em Pernambuco, nas regiões do Agreste e Litoral/Mata do Estado, o acumulado das precipitações em 2012 somou apenas $30 \%$ e $60 \%$ das médias climatológicas respectivas. Essa situação caracterizou a chegada dos efeitos da estiagem ao litoral e à Zona da Mata Pernambucanos. O final de 2012 e os três primeiros meses de 2013 foram caracterizados pela ocorrência de chuvas mal distribuídas no Sertão do Estado, com aumento de acumulação insignificante em praticamente todos os reservatórios utilizados para abastecimento de água. Segundo o mesmo trabalho, o período chuvoso entre 2013 e 2016 no litoral e na Mata aconteceu em situação de normalidade ou próxima a normalidade, o que permitiu a restauração do abastecimento normal para a região metropolitana do Recife. No semiárido, a situação de déficit hídrico nos mananciais se manteve. Segundo o

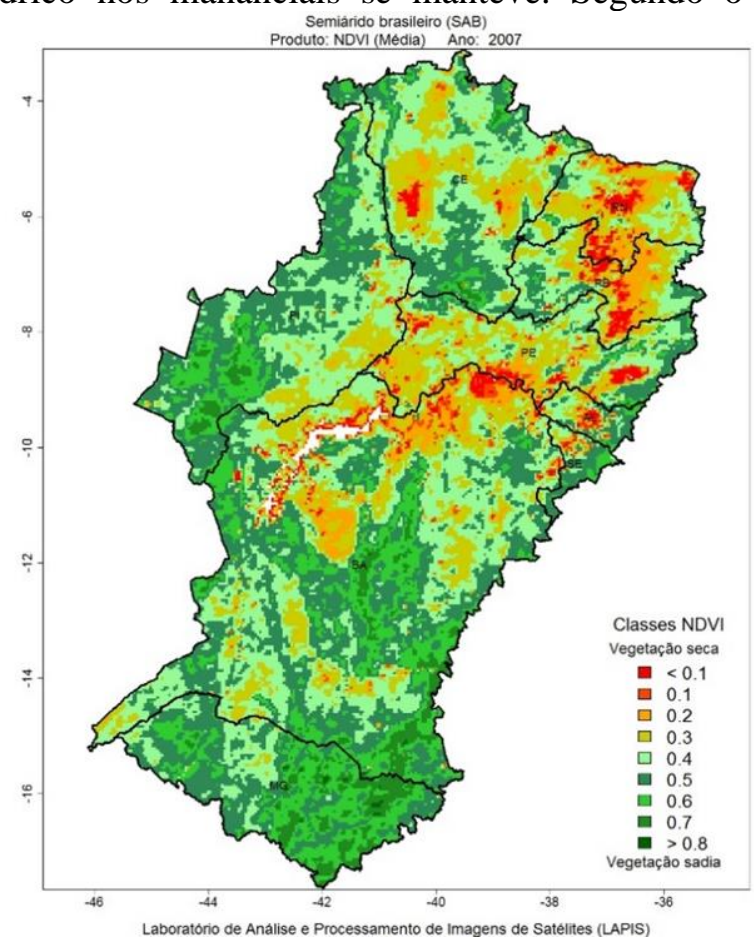

prognóstico para o verão, do INMET (2019), o nordeste brasileiro passou por cinco anos consecutivos de seca (2012-2016), e em alguns estados, como é o caso do Ceará, observou-se a maior seca desde o ano de 1910. Analisando as imagens referentes ao NVDI, entre 2007 a 2016, presentes na figura 16, observar-se que os municípios de Cabrobó, Dormentes, Belém de São Francisco, Ouricuri, Joaquim Nabuco, São Benedito do Sul e Palmares apresentaram os menores valores do NVDI, em relação a outros municípios do estado de Pernambuco, caracterizando-as como locais mais onde houve um período de seca mais forte. No ano de 2012, boa parte do estado de Pernambuco apresentou NDVI relativamente baixo, caracterizando esse período como um dos períodos mais secos, concordando com os resultados obtidos pelo índice de anomalia de chuvas, pois neste período, a maioria dos municípios analisados apresentou índice de anomalia de chuvas muito baixo, menores que -4 .

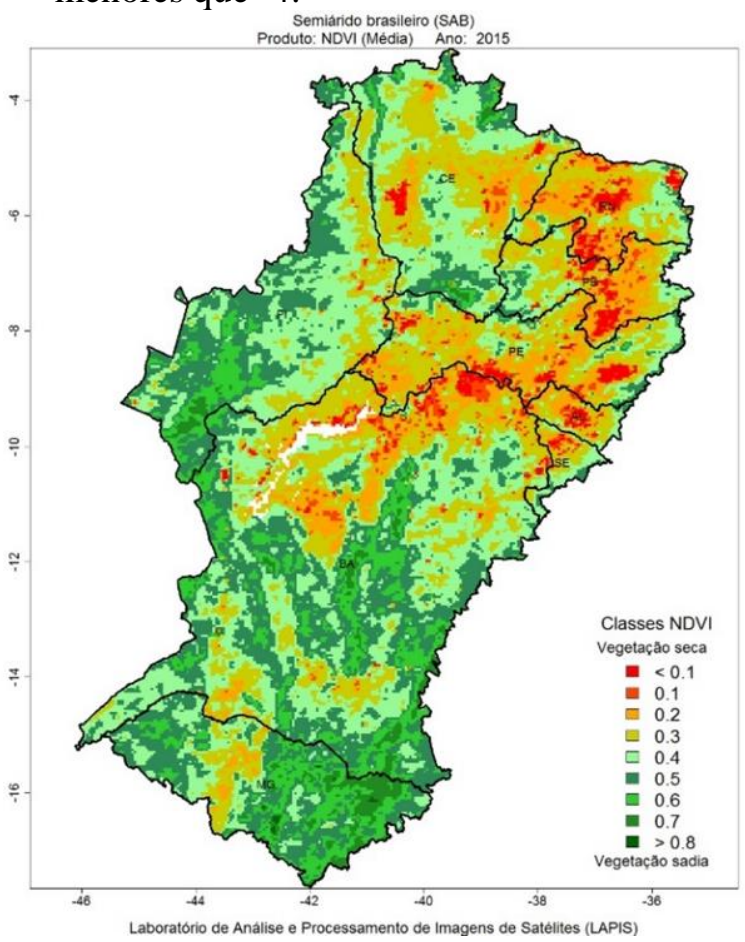

Figura 16. NVDI Médio de 2007 e 2016. Fonte: LAPIS (2019) 
Observando tanto a imagem referentes as áreas afetadas pela desertificação como a imagem referente as áreas susceptíveis a desertificação presente na figura 17 , observa-se um dos núcleos de desertificação localiza-se na região do São Francisco, próximo dos municípios de Belém de São frâncico, Cabrobó, Floresta, enquanto que a região que afetada pela desertificação com nível grave localiza-se no sertão Pernambucano,

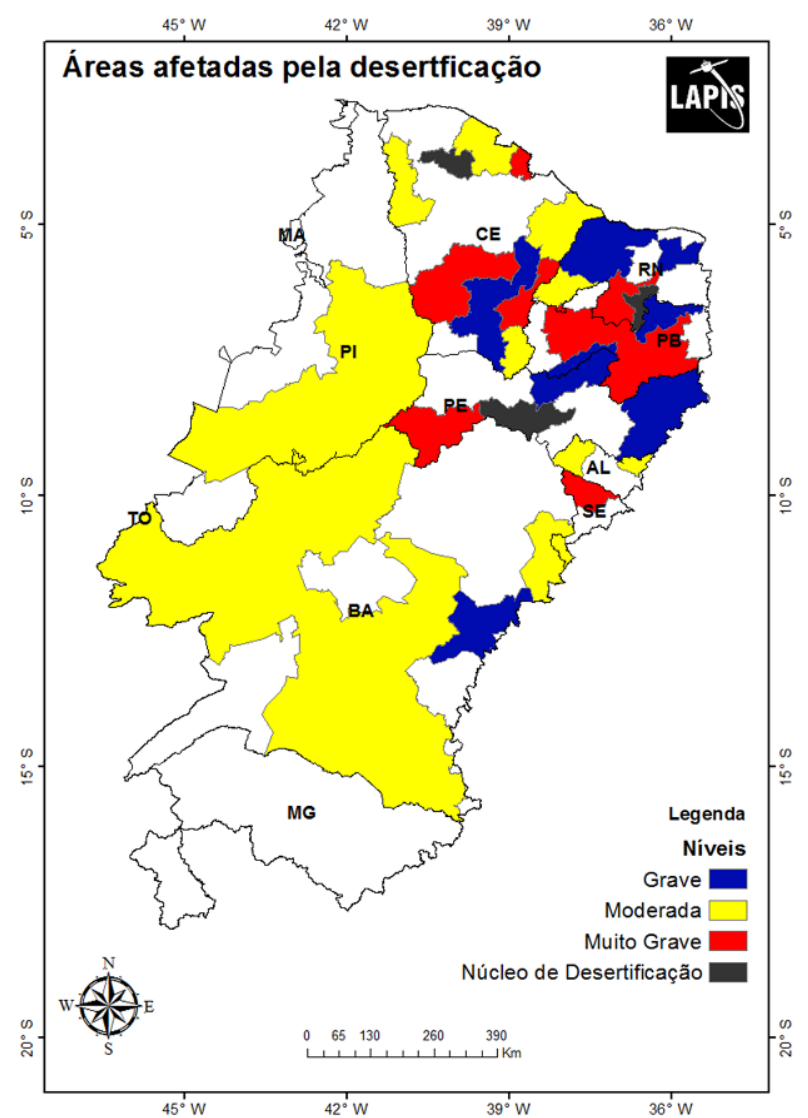

Figura 17. Áreas afetadas pela desertificação e áreas susceptíveis a desertificação. Fonte: LAPIS (2019)

Resultados da análise de tendência da precipitação pluviométrica

Analisou-se os resultados obtidos pelo software Trend em relação à série histórica de cada posto de precipitação, observamos que todos os postos apresentaram tendências significativas de queda. A analise do trabalho realizado por Silva (2013) e os relatórios publicados pelo Painel Intergovernamental de Mudanças Climáticas (IPCC, 2013), possibilitou a observação que é esperado que o aquecimento global venha a modificar os padrões pluviométricos em diversas

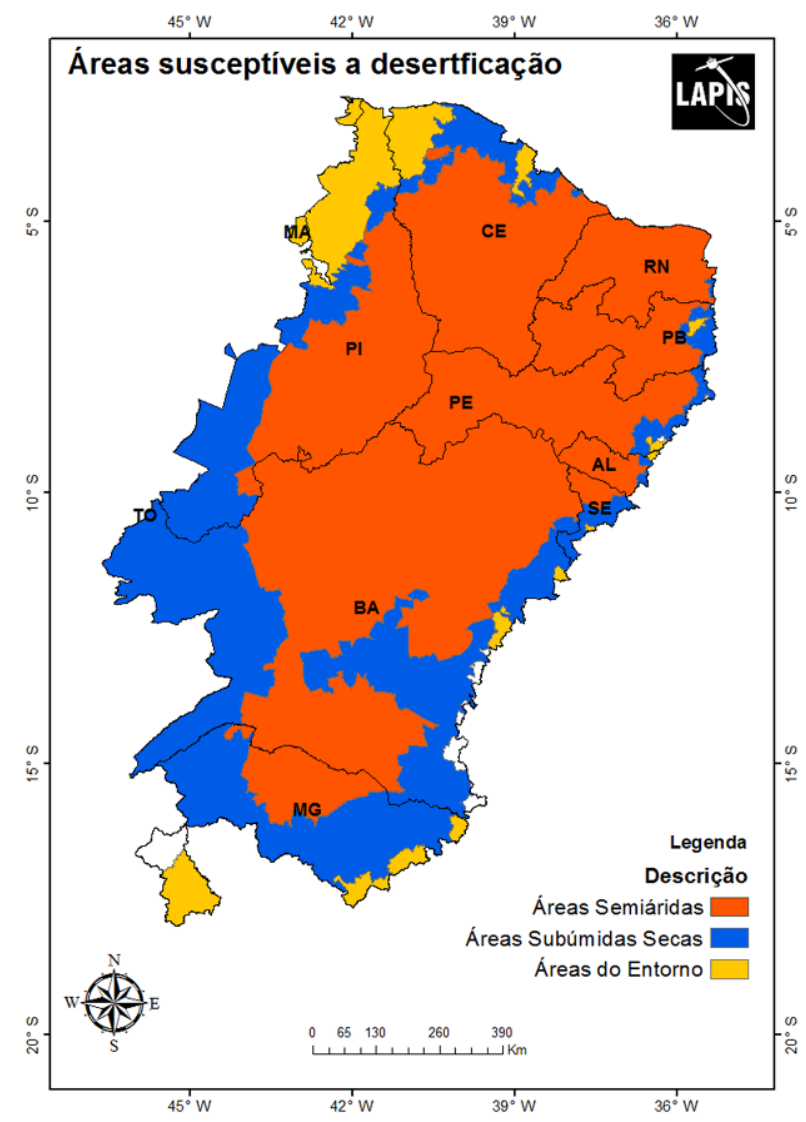

próximo aos municípios de Petrolina, Afrânio e dormentes. Algumas dessas áreas citadas obtiveram resultados, tanto do índice de anomalia de chuvas (IAC), como do índice de aridez (IA) e do índice de vegetação da diferença normalizada (NVDI) que mostram que essas áreas apresentaram indícios que indicam possíveis mudanças climáticas ocorrendo nestes locais.

regiões do mundo, diminuindo o volume das chuvas e aumentando a quantidade de fenômenos de seca, afetando principalmente regiões que dependem das atividades associadas à agricultura de subsistência e afetar a geração de energia hidroelétrica que ocorrem no estado de Pernambuco, onde a tendência de queda na precipitação total anual da intensidade média diária de chuvas, concordando com os resultados obtidos pelo Trend.

\section{Mesorregião: Região Metropolitana do Recife}


Tabela 3. Resultados da análise de tendência da precipitação pluviométrica

\begin{tabular}{|l|c|c|c|c|}
\hline \multicolumn{1}{|c|}{ Estatistica } & $\begin{array}{c}\text { Jaboatao dos } \\
\text { Guararapes }\end{array}$ & Camaragibe & Recife & Abreu e Lima \\
\hline Mann-Kendall & NS & S (0.05) & S (0.1) & S (0.1) \\
\hline Spearman's Rho & NS & S (0.05) & S(0.1) & S (0.1) \\
\hline Linear regression & NS & S (0.05) & S(0.1) & S (0.1) \\
\hline Cusum & NS & NS & NS & NS \\
\hline Cumulative deviation & NS & NS & NS & NS \\
\hline Worsley likelihood & NS & S (0.1) & S(0.1) & S (0.1) \\
\hline Rank Sum & NS & NS & NS & NS \\
\hline Student's t & NS & NS & NS & NS \\
\hline Median Crossing & S(0.05) & NS & NS & NS \\
\hline Turning Point & NS & NS & NS & NS \\
\hline Rank Difference & NS & NS & NS & NS \\
\hline Auto Correlation & NS & NS & NS & NS \\
\hline
\end{tabular}

Legenda: NS - Nenhuma significância estatística; S - significância estatística Fonte: Autores (2019).

Tabela 4. Análise de tendência da precipitação pluviométrica por posto.

\begin{tabular}{|l|c|}
\hline \multicolumn{1}{|c|}{ Posto Pluviometrico } & Analise de Tendencia \\
\hline Joboatao dos Guararapes & Os Dados Não Mostram Tendencias Estatisticamente Significativas \\
\hline Recife & Os Dados Mostram Tendencias Estatisticamente Significativas de Diminuição \\
\hline Abreu e Lima & Os Dados Mostram Tendencias Estatisticamente Significativas de Diminuição \\
\hline Camaragibe & Os Dados Mostram Tendencias Estatisticamente Significativas de Diminuição \\
\hline
\end{tabular}

Fonte: Autores (2019).

Mesorregião: Agreste de Pernambuco

Tabela 5. Resultados da análise de tendência da precipitação pluviométrica.

\begin{tabular}{|l|c|c|c|c|c|c|}
\hline \multicolumn{1}{|c|}{ Estatistica } & Belo Jardim & Bezerros & Caruauru & Garanhuns & $\begin{array}{c}\text { Santa Cruz do } \\
\text { Capibaribe }\end{array}$ & Surubim \\
\hline Mann-Kendall & S (0.1) & NS & S (0.1) & NS & NS & NS \\
\hline Spearman's Rho & S (0.1) & NS & S (0.05) & NS & NS & NS \\
\hline Linear regression & NS & NS & S (0.1) & NS & NS & NS \\
\hline Cusum & NS & NS & NS & NS & NS & NS \\
\hline Cumulative deviation & S(0.1) & NS & S (0.05) & NS & NS & NS \\
\hline Worsley likelihood & NS & NS & S(0.1) & NS & NS & NS \\
\hline Rank Sum & NS & NS & NS & NS & NS & NS \\
\hline Student'st & NS & NS & NS & NS & NS & NS \\
\hline Median Crossing & NS & S(0.01) & NS & S (0.05) & NS & NS \\
\hline Turning Point & NS & NS & NS & NS & NS & NS \\
\hline Rank Difference & NS & NS & NS & NS & NS & NS \\
\hline Auto Correlation & S(0.05) & NS & NS & NS & NS & NS \\
\hline
\end{tabular}

Legenda: NS - Nenhuma significância estatística; S - significância estatística Fonte: Autores (2019).

Tabela 6. Análise de tendência da precipitação pluviométrica por posto

\begin{tabular}{|l|r|}
\hline \multicolumn{1}{|c|}{ Posto Pluviometrico } & \multicolumn{1}{c|}{ Analise de Tendencia } \\
\hline Belo Jardim & Os Dados Mostram Tendencias Estatisticamente Significativas de Diminuição \\
\cline { 2 - 2 } Bezerros & Os Dados Não Mostram Tendencias Estatisticamente Significativas \\
\cline { 2 - 2 } Caruauru & Os Dados Mostram Tendencias Estatisticamente Significativas de Diminuição \\
\cline { 2 - 2 } $\begin{array}{l}\text { Santa Cruz do Capibaribe } \\
\text { Surubim }\end{array}$ & Os Dados Não Mostram Tendencias Estatisticamente Significativas \\
\cline { 2 - 2 } & Os Dados Não Mostram Tendencias Estatisticamente Significativas \\
\hline
\end{tabular}
Fonte: Autores (2019).

Mesorregião: Sertão Pernambucano

Tabela 7. Resultados da análise de tendência da precipitação pluviométrica. 


\begin{tabular}{|c|c|c|c|c|c|}
\hline Estatistica & Afogados do Ingazeira & Betania & Bodoco & Brejinho & Exu \\
\hline Mann-Kendall & NS & $\mathrm{S}(0.1)$ & NS & NS & NS \\
\hline Spearman's Rho & NS & $\mathrm{S}(0.1)$ & NS & NS & NS \\
\hline Linear regression & NS & $S(0.1)$ & NS & NS & NS \\
\hline Cusum & NS & NS & NS & NS & NS \\
\hline Cumulative deviation & $S(0.1)$ & $\mathrm{S}(0.05)$ & NS & NS & NS \\
\hline Worsley likelihood & NS & $\mathrm{S}(0.05)$ & NS & NS & NS \\
\hline Rank Sum & $\mathrm{S}(0.05)$ & $S(0.01)$ & NS & NS & NS \\
\hline Student's t & $S(0.05)$ & $S(0.05)$ & NS & NS & NS \\
\hline Median Crossing & NS & NS & NS & NS & $\mathrm{S}(0.05)$ \\
\hline Turning Point & NS & NS & NS & $S(0.01)$ & NS \\
\hline Rank Difference & $\mathrm{S}(0.1)$ & $S(0.05)$ & NS & $\mathrm{S}(0.01)$ & NS \\
\hline Auto Correlation & $S(0.05)$ & $S(0.01)$ & NS & $S(0.01)$ & NS \\
\hline
\end{tabular}

Legenda: NS - Nenhuma significância estatística; S - significância estatística

Fonte: Autores (2019).

Tabela 8. Resultados da análise de tendência da precipitação pluviométrica.

\begin{tabular}{|l|c|c|c|c|c|}
\hline \multicolumn{1}{|c|}{ Estatistica } & Arcoverde & Serra Talhada & Ibimirim & Salgueiro & Ouricuri \\
\hline Mann-Kendall & NS & NS & S (0.1) & NS & NS \\
\hline Spearman's Rho & NS & NS & S (0.1) & NS & NS \\
\hline Linear regression & NS & NS & NS & NS & NS \\
\hline Cusum & NS & NS & S (0.05) & NS & NS \\
\hline Cumulative deviation & NS & NS & S (0.05) & S (0.1) & NS \\
\hline Worsley likelihood & NS & NS & NS & NS & NS \\
\hline Rank Sum & NS & NS & S (0.05) & NS & NS \\
\hline Student's t & NS & NS & S(0.1) & NS & NS \\
\hline Median Crossing & NS & NS & NS & NS & NS \\
\hline Turning Point & NS & NS & NS & NS & NS \\
\hline Rank Difference & NS & NS & NS & S (0.1) & NS \\
\hline Auto Correlation & NS & NS & S (0.1) & S (0.1) & NS \\
\hline
\end{tabular}

Legenda: NS - Nenhuma significância estatística; $\mathrm{S}$ - significância estatística

Fonte: Autores (2019).

Tabela 9. Análise de tendência da precipitação pluviométrica por posto.

\begin{tabular}{|l|c|}
\hline \multicolumn{1}{|c|}{ Posto Pluviometrico } & Analise de Tendencia \\
\hline Afogados do Ingazeira & Os Dados Não Mostram Tendencias Estatisticamente Significativas \\
\hline Betania & Os Dados Mostram Tendencias Estatisticamente Significativas de Diminuição \\
\hline Bodoco & Os Dados Não Mostram Tendencias Estatisticamente Significativas \\
\hline Brejinho & Os Dados Não Mostram Tendencias Estatisticamente Significativas \\
\hline Exu & Os Dados Não Mostram Tendencias Estatisticamente Significativas \\
\hline Arcoverde & Os Dados Não Mostram Tendencias Estatisticamente Significativas \\
\hline Serra Talhada & Os Dados Não Mostram Tendencias Estatisticamente Significativas \\
\hline Ibimirim & Os Dados Mostram Tendencias Estatisticamente Significativas de Diminuição \\
\hline Salgueiro & Os Dados Não Mostram Tendencias Estatisticamente Significativas \\
\hline Ouricuri & Os Dados Não Mostram Tendencias Estatisticamente Significativas \\
\hline
\end{tabular}

Fonte: Autores (2019). 


\section{Conclusões}

Os índices climáticos utilizados tiveram resultados compatíveis com a realidade, visto que tanto as áreas afetadas como as áreas susceptíveis pela desertificação apresentaram índices que indicaram zonas climáticas áridas e semiáridas, bem como, baixos valores de precipitação acumulada como também grandes quantidades de dias sem precipitação, aumentando as chances de ocorrência de mudanças climáticas. Mesmo os índices climáticos utilizados apresentarem diferenças em suas metodologias, seus resultantes foram semelhantes, colaborando para a análise de possíveis mudanças climáticas. Nem todos os postos pluviométricos apresentaram tendências significativas, porém aqueles que não apresentaram tendências possuem características relacionados tanto ao seu regime de precipitação, como a precipitação acumulada e a quantidade de dias sem precipitação, como valores respectivos ao índice de anomalia de chuva, índice de aridez e o Índice de Vegetação da Diferença Normalizada que permitem analisar possíveis cenários a longo prazo. Alguns municípios como Belém de São Francisco, Floresta e Dormentes, além de apresentarem, baixos valores nos índices climáticos utilizados, também apresentaram tendências de queda na precipitação média anual, apresentando uma chance maior de ocorrer seca ou período de estiagem severo, que podem trazer prejuízos diversos tanto nas biodiversidades locais como nas atividades econômicas desenvolvidas nestes locais como a pecuária e agricultura.

\section{Agradecimentos}

Os autores agradecem ao Instituto nacional de meteorologia, a agência Pernambucana de águas e clima e o laboratório de análise e processamento de Imagens e satélite por disponibilizar os dados climáticos das estações estudadas e os dados de índice de vegetação da diferença normalizada já processados, e também a Universidade federal de Pernambuco pela disponibilidade do espaço no laboratório de hidráulica do departamento de recursos hídricos.

\section{Referências}

AGÊNCIA NACIONAL DE ÁGUAS. Superintendia de Informações Hidrológicas. Águas Subterrâneas. Brasília (DF): ANA, agosto 2002, 85 p.

AGÊNCIA PERNAMBUCANA DE ÁGUAS E CLIMA. Dados dos postos pluviométricos. Recife: APAC, 2019.Disponível em:http://www.apac.pe.gov.br/meteorologia/m
onitoramento-pluvio.php.Acesso em: 16mai. 2019.

AGÊNCIA PERNAMBUCANA DE MEIO AMBIENTE. Plano Estadual de Mudanças Climáticas - (Proposta para Debate com a Sociedade). Recife: CPRH, 2011. 94 p.

CEPED - Centro de Estudos e Pesquisas em Engenharia e Defesa Civil. Disponível em: http://www.ceped.ufsc.br/. Acesso: 14 de maio 2019.

Freitas, M. A V. O estado das águas no Brasil: Perspectivas de Gestão e da Informação de recursos Hídricos. In: ANEEL. Brasília - DF, 1999.

INMET - Instituto Nacional de Meteorologia. Dados meteorológicos, estações automáticas, PE-Recife. Disponível em: http://www.inmet.gov.br/portal/index.php?r=es tacoes/estacoesAutomaticas. Acesso: 16 de maio 2019.

IPCC. Climate Change 2013: the physical science basis. Contribution of Working Group I to the Fifth Assessment Report of the Intergovernmental Panel on Climate Change [Stocker, T.F., D. Qin, G.-K. Plattner, M. Tignor, S.K. Allen, J. Boschung, A. Nauels, Y. Xia, V. Bex and P.M. Midgley (eds.)]. Cambridge: Cambridge University Press, 2013. $1535 \mathrm{p}$.

LAPIS - Laboratório de Análise e Processamento de Imagens e Satélite. Disponível em: http://www.lapismet.com.br/. Acesso: 14 de maio 2019.

Nimer, E. Pluviometria e recursos hídricos dos estados de Pernambuco e Paraíba. Rio de Janeiro: IBGE, 1979. 120p.

Silva, R. O. B.; Montenegro, S. M. G. L.; Souza, W. M. de. Tendências de mudanças climáticas na precipitação pluviométrica nas bacias hidrográficas do estado de Pernambuco. Eng. Sanit. Ambient., v.22 n.3, p. 579-589, mai./jun. 2017.

Silva, R. O. B. Tendências de mudanças climáticas na precipitação pluviométrica no estado de Pernambuco. 2013. 94 f. Dissertação (mestrado) - UFPE, Centro de Tecnologia e Geociências, Programa de Pós-graduação em Engenharia Civil, 2013.

Yevjevich, V. Probability and statistics in hydrology. Fort Collins: Water Resources Publication, 1972. 276p. 